\title{
CHARACTERIZATION OF TYPE 304L STAINLESS STEEL SOLID-STATE CLOSURE WELDS FOR RADIOACTIVE WASTE CONTAINMENT
}

by

West, S.L.

Westinghouse Savannah River Company

Savannah River Site

Aiken, South Carolina 29808

A document prepared for 27TH ANNUAL MEETING OF THE INTERNATIONAL METALLOGRAPHIC

SOCIETY/MICROSTRUCTURAL SCIENCE, VOL. 22 at Montreal, Quebec, Canada from 24 Jul-27 Jul 1994.

DOE Contract No. DE-AC09-89SR18035

This paper was prepared in connection with work done under the above contract number with the U. S.

Department of Energy. By acceptance of this paper, the publisher and/or recipient acknowledges the U.S. Government's right to retain a nonexclusive, royalty-free license in and to any copyright covering this paper, along with the right to reproduce and to authorize others to reproduce all or part of the copyrighted paper.

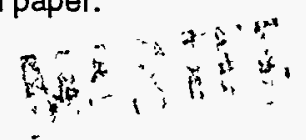




\section{DISCLAIMER}

This report was prepared as an account of work sponsored by an agency of the United States Government. Neither the United States Government nor any agency thereof, nor any of their employees, makes any warranty. express or implied. or assumes any legal liability or responsibility for the accuracy. completeness, or usefulness of any information, apparatus, product, or process disclosed. or represents that its use would not infringe privately owned rights. Reference herein to any specific commercial product, process, or service by trade name, trademark. manufacturer, or otherwise does not necessarily constitute or imply its endorsement. recommendation, or favoring by the United States Government or any agency thereof. The views, and opinions of authors expressed berein do not aecessarily state or reflect those of the United States Government or any agency ihereof.

This report has been reproduced directly from the best available copy.

Available to DOE and DOE contractors from the Office of Scientific and Technical Information. P. O. Box 62. Oak Ridge. TN 37831; prices available from (615) $576-8401$.

Available to the public from the National Technical Information Service, U. S. Deparment of Commerce, 5285 Port Royal Rd. Springfield. VA 22161 


\section{DISCLAIMER}

Portions of this document may be illegible in electronic image products. Images are produced from the best available original document. 


\title{
CHARACTERIZATION OF TYPE 304L STAINLESS STEEL SOLD-STATE CLOSURE WELDS FOR RADIOACTIVE \\ WASTE CONTAINMENT
}

\author{
S. L. WEST ${ }^{1}$
}

\begin{abstract}
Radioactive wastes, generated during years of nuclear materials production, will be vitrified in glass and sealed in canisters. These cylindrical canisters are fabricated from $0.375^{\prime \prime}(9.5 \mathrm{~mm})$ thick Type 304L stainless steel plate and are 24" $(61 \mathrm{~cm})$ in diameter and $118^{\prime \prime}(3 \mathrm{~m})$ tall with a forged nozzle. The canisters will be sealed by resistance upset welding a $5 "(12.7 \mathrm{~cm})$ diameter, 0.5 " $(1.27 \mathrm{~cm})$ thick, slightly oversized plug into the nozzle. This process lends itself to automation and remote operation which will minimize personnel radiation exposure.

A parametric study recommended a range of production welding variables based on mechanical tests and metallography. Microstructures were characterized by sectioning test welds at two locations for optical metallography and scanning electron microscopy (SEM). Intentionally "cold" welds produced with low currents and short times exhibited insufficient interface length and lack-ofbonding. At very high currents, long weld times and low force, maximum heating occurred with significant melting at the top; which makes process stability a concern. All welds made between these extremes exhibited predominantly solid-state bonding. Little variation in microstructure between welds was found along much of the interface with changes in current, force and time. Hardness traverses across the welds showed higher values at the interface, indicative of the worked microstructure. Crevices formed at the top and bottom during plastic flow of the material, and grain sizes varied along the interface from differences in dynamic recrystallization and grain growth. The degree of melting at the top was the most significant difference among welds made within the recommended parameter range.
\end{abstract}

${ }^{1}$ Materials Technology Section, Savannah River Technology Center, Westinghouse Savannah River Company, Aiken, SC 
Page 2

\section{INTRODUCTION}

The Defense Waste Processing Fac'-1ity (DWPF) canisters will be filled with radioactive waste glass and sealed oy resistance upset welding a plug into the canister nozzle. These canistars are cylinders approximately $2 \mathrm{ft}$ in diameter and $10 \mathrm{ft}$ tall fabricated from 0.375 " thick plate with a forged bottom and nozzle joined to the cylinder by girth welds. All componeats are fabricated from Type 304L stainless steel. The plug is $0.5^{\prime \prime}$ thick and $5 "$ in diameter, slightly oversize for the nozzle opening (interference fi:.. With long term storage of the filled canisters at SRS likely, it is essential to assure the integrity of the nozzle seal weld. From a structural standpoint, very little load will be -laced on the joint, but the potential for corrosion or other environmental assisted degradation is of greater concern, and will be addressed in future studies. A high integrity joint will provide the greatest margin against degradation.

Resistance upset welding provides a reliable means for sealing the canisters and is well suited for use in the DWPF environment where its simplicity lends itself to remote, automatic operation. It is generally a solid-state process (no melting) using high temperature and force to bond materials over a very short time period $(<2.5 \mathrm{sec}$ in this case). These short times at elevated temperature also minimize the formation of a heat-affected zone in the material surrounding the weld. Grain growth across the interface subsequent to dynamic recrystallization during high temperature deformation appears to be an important mechanism by which the bonding occurs. Plastic deformation is, therefore, a key element in the formation of these solid-state welds in that it promotes recrystallization. The role which solid-state diffusion plays in the process is uncertain due to the short times at elevated temperature. The role of diffusion is also difficult to determine with materials having essentially the same composition, as in this application. Little composition gradient exists across the interface to indicate a diffusion distance. Regardless of the specific mechanism(s) by which joining is achieved, solid-state welds in an austenitic stainless steel exhibit a single phase structure (austenite) compared to duplex structures (austenite and retained delta ferrite) and associated local variations in composition and properties exhibited by fusion welds. Solid-state welds are also less susceptible to volumetric defects such as porosity from solubility changes during solidification of fusion welds. Good strength and ductility are demonstrated by properly. made solid-state welds.

A set of welding parameters has been developed and demonstrated to provide sound welds using full-scale mock-ups of the plug to nozzle weld. The variables involved are welding current, time (cycles of $60 \mathrm{~Hz}$ signal) and electrode force. During the experimental portion of this work (Phase 1), welds were made in three distinct groups (parts A, B and C) with two sets of parameters which varied around different central points. The criteria for acceptance of the weld parameter study included a requirement that a minimum bond interface length be assured and that there be zero flaws along this interface [1], which will be interpreted below. Phase 2 of this parametric study will be a future procedure qualification run of 100 welds performed at DWPF during cold runs. 
Results of Phase 1 of the parametric study demonstrated a range of acceptable parameters through leak tests, tensile tests, burst tests, fracture tests and measurements of bond length [2]. A limited number of bend tests were also completed, but these results were inconsistent with other indications of weld quality and the tests were replaced by fracture tests. Subsequent review by the DWPF Joint Test Group (JTG) called for clarification of the final report by stating specifically whether the microstructure examination results were acceptable [3]. Two previous metallurgical examination reports have addressed parts $A$ and $B$ [4] and the fracture tests performed during part $\mathrm{C}$ [5] of the parametric study, respectively. Metallography was completed on all test specimens, but documentation of the microstructures for the final parameter envelope (part C) and the extremes outside the envelope had not been completed. Therefore, this report supplements the existing reports with microstructural evidence of weld quality. At the request of DWPT, MTS personnel performed this work in support of the Equipment and Materials Technology Department (E\&MTD) Special Processes Section (SPS), who did the original work. This short task (E\&MTD Task No. 22327) documents metallographic data verifying the acceptability of welds from the recommended parameter space.

Since acceptable weld quality has not been defined for this program using standard welding terminology, an attempt to define "acceptable" will be made here. Welding terminology makes a distinction between a discontinuity and a defect. A discontinuity is "an interruption in the typical structure of a weldment, such as a lack of homogeneity in the mechanical, metallurgical, or physical characteristics of the material or weldment" [8]. A discontinuity becomes a defect when it "by nature or accumulated effect renders a part or product unable to meet minimum applicable acceptance standards or specifications" [9]. Thus, a discontinuity does not imply rejection of a part, but a defect does.

In the DWPF canister closure welds, the requirement is zero flaws at the weld interface, which must be a minimum of 0.335 " long [1]. No magnification was specified for identification of flaws. During this work, this requirement has been interpreted as zero discontinuities at the weld interface between the upper and lower crevices, as observed at $100 \mathrm{X}$ to $500 \mathrm{X}$ on a metallographic sample ("acceptable"). These crevices have been excluded from evaluation as they are beyond the area of interest, but are inherent to the process since metal is extruded from the joint interface area, creating the nascent surfaces that bond. Since there is no constraint in the metal extruded beyond the parts (termed "flash"), the unbonded portion of the interface separates. The crevice at the bottom is not associated with the bond line, but is located between the canister nozzle and material extruded from the joint. Between these crevices, the bond should appear "solid" without voids or interruptions to be acceptable.

\section{OBJECTIVES}

The specific objective of this work was to document the microstructural analysis of welds made during the parametric study. Other objectives included the identification of any relationships among the microstructure, welding variables and mechanical properties. Also, it was desirable to understand the trends in the 
Page 4

microstructure as a parameter is shifted from a set-point. In addition, this work provides some background information for subsequent weld characterization and corrosion tests to be performed once DWPF begins to pour glass into canisters [6].

\section{PROCEDURE}

Existing metallographic specimens were selected which included welds made both within the range of acceptable parameters and the initially broader parameter range outside this acceptable range. Some of the samples representing welds made with even greater extremes in parameters were not available because these samples underwent hydrostatic burst testing and were thus destroyed.

Figure 1 is a diagram of parameters, showing a larger outer cube used for parts A and $B$ (samples KS01 - KS14) and the smaller inner cube of acceptable welds used for part C (samples KS15 - KS46) [2]. For this study, only corner points and center points within the parameter spaces were examined. Only part A welds from the outer parameter space were available for examination as all part B welds were hydrostatic burst tested. Duplicate welds were made in part C so both metallography and mechanical tests could be performed.

Two metallographic specimens were available from each weld (designated C1 and C2). These were visually examined to verify that the weld interface and profile were equivalent in both samples, and one was selected for further examination. Samples were cleaned, analyzed and photographed at approximately 7X to 500X via optical microscopy (Appendix A lists the negative numbers for all photomicrographs presented here). The length of the bond interface was covered by taking photomicrographs near the top, bottom and middle of the weld. This was sufficient to cover the range of microstructures observed. Grain size was determined qualitatively by comparison with ASTM E112 nominal grain size photomicrographs from the Metals Handbook [7]. Grain sizes were not quantitatively determined since there was no obvious difference in grain size among welds made using differing welding parameters.

Also examined were a set of seven samples (CER 1 - CER 7) run with identical settings to investigate different ceramic insulator materials. The parameter settings were slightly reduced from settings at the center of the recommended range. These welds were characterized to evaluate the repeatability of the microstructures and the effect of slight process adjustments.

\section{RESULTS}

In general, little evidence of poor bond quality was found except in those welds which were intentionally very "cold" and resulted in a short interface length and unbonded regions. Starting microstructures were significantly different than those of the weld and surrounding region of plastic flow. The nozzle was a forged part while the plug was machined from rolled plate. Both exhibited a fairly equiaxed grain structure, but the plug material had a finer grain size (Figure 2). Superficial hardness test results reported in [4] showed a slightly higher hardness in the cap material. 
Page 5

Figure 3 shows a schematic of the plug to nozzle weld cross section (A) and the region of the bond area (B). As stated previously, the plug is slightly larger than the nozzle opening, resulting in the extrusion of material from the joint (flash). The shaded region in (B) shows the approximate location and concentration of plastic flow in the material. A more substantial crevice is seen at the bottom than at the top of these welds. Typically grain size was seen to vary from top to bottom, with the largest grains the top and smallest grains at the bottom.

\section{Description of Weld Microstructures}

\section{PART A}

The weld made with minimum parameters, low force, low current and short time (KS06 in Figure 1), was obviously "cold" and did not meet the minimum bond length (throat) requirement. However, as shown in Figure 4, regions of the weld actually appeared to be well bonded. Note that the materials on each side of the interface are reversed between low and high magnification photos due to different microscopes being used. When weld force was increased from this set point with current and time held constant, the quality of the weld actually decreased (weld KS01 in Figure 5). Intermittent areas of poor bonding, as indicated by a continuous dark feature (discontinuity) on the photomicrographs, were evident across the entire bond length and, therefore, this weld did not meet the acceptance criteria. However, this weld did demonstrate a reasonable tensile strength [2], so bonding of some regions did occur. Other studies have shown that a bond line can be visible along a solid-state weld interface and yet the weld has significant strength and/or ductility $[10,11,12]$.

All other welds within the test matrix exhibited much longer bond lengths and good bonding between the crevices. At the center of the outer box is sample KS05 (Figure 6), welded at $96400 \mathrm{lbs}$ and $239000 \mathrm{Amps}$ for 90 cycles. This weld exhibited some partial melting in the plug material near the top and melting in the canister material at the edge of the extruded metal. At low magnification (Figure 6A), obvious flow lines in the plug material versus more subtle flow lines in the nozzle material make the bond line readily apparent. Note the formation of crevices as described previously. At higher magnification, the photomicrographs show a solid bond line with no voids. A hot worked structure is evident, as grain size varied along the length of the weld interface, indicating variations in plastic flow and temperature responsible for recrystallization.

Table 1 presents the weld bond length dimensions, measured from the photomicrographs for comparison with the 0.335 " requirement, and the approximate grain sizes along the interface of all welds examined. The extremely fine grains near the bottom of the weld indicate the high degree of constraint at that part of the joint and the occurrence of dynamic recrystallization The larger grains at the top indicate less constraint and higher temperature, also manifested as melting. Figure 6 also shows that much of the plastic flow was concentrated in the plug material, which is probably due to constraint and greater heat sink on the canister side. 
Page 6

The most melting was observed in sample KS02, which was welded at peak current and time, but minimum force (Figure 7). This sample exhibited significant melting at the top, but had a solid bond line and was one of the initial samples to pass a bend test. A potential concern of operating in this range of parameters is the stability of the process, which will be discussed later. By increasing the force to maximum (with the same current and time - sample KS07), most of the melting was eliminated without producing a poor bond (Figure 8). Sample KS07 was the only other weld to pass a bend test (two out of two tests). Sample KS08, with a shorter weld time than KS02 at the same current and force, also exhibited reduced melting and sufficient bonding. Thus, either higher force or shorter weld time may be used to reduce melting, if desired. However, samples with less melting either failed a bend test or passed on one out of two tests while exhibiting sound microstructures. Variables other than microstructure must have an effect on the results. In summary, the only welds from the outer box of weld parameters from Figure 1 with poor bonding were those at the lowest current, particularly when the force was high.

\section{PART C}

All of the welds produced in Part C of the Parametric Study (inner box in Figure 1) exhibited weld interfaces without voids or other discontinuities. Some melting is evident at the top of all samples except those welded at the lowest current setting (226000 Amps). This melting is not foreseen as a problem from a strength or integrity standpoint. Corrosion tests to be performed on welds removed from glass filled canisters will address any potential impact of melting or crevices on the life of the canisters [6]. Sample KS41 (Figure 9) represents the minimum parameters from the inner, recommended parameter space of Figure 1. Another weld (KS15) made with the same machine settings exhibited the highest burst strength. The bond line of KS41 is visible at the center of the sample, but this appears to be due to an accumulation of inclusions (stringers present from the original ingot) at the interface during welding. All of the other welds made at this low current level also had solid bond lines, including KS37 made with maximum force, in contrast to KS01 from part A (Figure 5). Sample KS33 (low current and force, long time) was the only sample welded with low current to exhibit some partial melting at the top.

Three welds were examined from the central point of the parameter space (90000 lbs, 248000 Amps, 95 cycles), all of which appeared to be fairly consistent from a microstructural standpoint. Figure 10 presents one such weld, sample KS19, which exhibited some melting at the top where material was extruded from the nozzle. A very small crevice was apparent at the top, but the bond became solid just a short distance into the weld. The bond in the center was solid, with grain growth evident across the interface (Figure 10E). The bond at the bottom was also solid well beyond where the crevice began. There was very little microstructural difference between this central position weld and that of the larger cube (KS05). The grain size was slightly finer at the center of KS05, but this is not significant and probably an effect of higher force, lower current and shorter time, all of which tend to promote a cooler weld. 
Page 7

Of the part $\mathrm{C}$ welds made at the peak current of 270000 Amps, only sample KS44 (Figure 11) shows any unusual characteristics. This weld was also made with low force and maximum time for the parameter space and, as such, was similar to KS02 (Figure 7). Significant melting occurred at the top on both sides of the bond line. The bond itself was sound, with no voids or discontinuities. Again, a decrease in weld time or increase in force for the other high current welds was effective in reducing the quantity of melting observed.

\section{CERAMIC RING WELDS}

As mentioned, this set of samples was run in the region of slightly reduced parameters relative to the central point to investigate different ceramic insulator materials. This set of seven samples was welded with a force of $75000 \mathrm{lbs}$, a current of $240000 \mathrm{Amps}$ and a duration of 90 cycles, versus $90000 \mathrm{lbs}, 248000 \mathrm{Amps}$ and 95 cycles. The process parameters showed good repeatability, as did the microstructures. Figure 12 presents the microstructure of such a weld. This weld exhibited slightly less melting at the top than did KS19 (Figure 10), as well as a slightly smaller grain size. No other significant characteristics were apparent.

\section{DISCUSSION}

\section{Relationship of Microstructures to Welding Parameters}

In general, the weld microstructures were not significantly affected by parameter variations within the inner cube of recommended parameters. No obvious correlations between parameters and interface length or grain size were apparent. The degree of melting was the most obvious effect, with an increase in melting produced by high current and time and low force. This melting is at the top of the weld at the outer edge of the upset area. Melting is not necessarily at the weld interface. No deleterious effect of this melting has been identified. However, large amounts of melting may result in deleterious operating conditions such as electrode sticking or wear, or ejection of molten metal (spatter). Weld interface quality was satisfactory throughout the weld parameter range in the inner cube of recommended parameters.

In the original, extended parameter space, low current significantly reduced bond length. Weld interface quality at low current remained high for low force but was poor for high force. At low current and high force, weld interface quality was sacrificed due to less concentration of heat at the weld interface. Another less significant effect was the slight variation in grain size, which is a function of plastic flow, temperature and time at temperature.

\section{Relationship of Microstructures to Properties}

All of the welds from the recommended parameter space exhibited good tensile strengths. This result is a reflection of the good bond quality and bond length exhibited by these welds.

There was some variation in weld burst strengths, which ranged from 5700 to 7100 psi. Welds made at low current exhibited burst pressures in excess of 6000 psi in three out of four cases. Welds made at high current and low force exhibited 
Page 8

higher burst pressures than those at high current and high force. This is undoubtedly due to the higher heat at the weld interface for lower force welds. The difference in observed bond quality for the high and low force welds was too subtle to explain the difference in these properties.

Based on the observed microstructures, the bend test results reported in the parametric study are difficult to explain (Table 2 of [2]). Those samples made with low current and short time (KS01, KS06) were not well bonded, lacked sufficient bond length and failed. Welds KS09 and KS03, welded with low current, but long time were inconclusive with one failure each. The reason for failure of any of the other welds, especially the complete failure of KS05 at the center of the parameter space is not evident based on the microstructure. Most of these welds exhibited good strength in tensile tests, with failure in the base metal. The influence of melting is also difficult to estimate since it occurred in only one region of the welds. The geometry of the bend test specimens and the depth of machining used to remove crevices may be a critical concern in these tests.

\section{Process Recommendations Based on Microstructures/Properties}

The results of this work indicate that any combination of parameters within the recommended range will produce acceptable welds. However, previous results have shown a general trend for better mechanical properties with forces lower than maximum. Use of lower current with lower forces would also reduce the tendency for melting, if considered significant. The sum of these factors suggests that the preferential welding set-point be shifted to the left and down from the center of the parameter space. Results from the ceramic insulator material test welds (Figure 12), which used a set-point shifted in this manner, indicate less melting and a smaller grain size may be possible with this shift. Whether such minor changes in microstructure would have a beneficial effect on the long-term service of the canisters is uncertain.

\section{CONCLUSIONS}

The following general conclusions can be made based upon the examination of the selected metallographic specimens.

- All of the welds produced using parameters within the recommended ranges from part $\mathrm{C}$ of the parametric study meet the acceptance criteria of minimum interface length and no voids along that section of weld interface.

- The most obvious microstructural difference observed for these welds is the degree of melting at the top, especially where material is extruded from the canister nozzle.

- The variability in mechanical properties of the original test welds can not be easily explained by the microstructures, but may be more a function of geometry and the inherent crevices. 
Page 9

- Selection of a welding set-point to the left and down from the center of the parameter space may have a slight, positive influence on the properties of the resultant welds.

\section{FUTURE WORK}

The potential impact of the inherent crevices and/or melting or other microstructural variations on the service life of the canister will be investigated in an independent task [6].

\section{ACKNOWLEDGEMENTS}

T. B. Curtis and other Materials Consultation staff performed the photomicroscopy and D. R. Nelson assisted in preparation of the table and figures.

\section{REFERENCES}

1. E. W. Holtzscheiter, "Technical Issues and SRTC Assistance for Welder Parametric Study (U)," OPS-DTF-920046, Westinghouse Savannah River Company, Aiken, SC, October 6, 1992.

2. B. J. Eberhard, "DWPF Canister Weld Parametric Study Test Completion," SRT-SPS-930084, Rev. 1, Westinghouse Savannah River Company, Aiken, SC, June 3, 1993.

3. DWPF Joint Test Group Meeting Minutes, JTG-93-032, Westinghouse Savannah River Company, Aiken, SC, October 6, 1993.

4. P. A. Kestin, "Metallurgical Examination of Phase I DWPF Canister Closure Welds (U)," SRT-MTS-935005, Westinghouse Savannah River Company, Aiken, SC, January 12, 1993.

5. P. A. Kestin, "Examination of Part C - Phase I Parametric Study Canister Welds (U)," SRT-MTS-935063, Westinghouse Savannah River Company, Aiken, SC, March 31, 1993.

6. S. L. West, K. J. Imrich and W. R. Kanne, Jr., "Characterization of DWPF Canister Welds and Labels, and Estimates of Service Life (U)," Task Plan SRTMTS-93-4031, Westinghouse Savannah River Company, Aiken, SC, May 19, 1993.

7. Metals Handbook, p. 4, Vol. 7, 8th Edition, American Society for Metals, Metals Park, OH, 1972.

8. Welding Handbook, p. 292, Vol. 1, 7th Edition, American Welding Society, Miami, 1976.

9. Welding Handbook, p. 291, Vol. 1, 7th Edition, American Welding Society, Miami, 1976. 


\section{Page 10}

10. W. R. Kanne, Jr., "Resistance Welding Oxidized Parts," DPST-83-1033, E. I. du Pont de Nemours \& Co., Savannah River Plant, Aiken, SC, March 18, 1983.

11. W. R. Kanne, Jr., "Microstructural Analysis of Solid-State Resistance Welds (U)," WSRC-MS-93-008, Westinghouse Savannah River Company, Aiken, SC, August, 1993.

12. S. L. West, "Endeavor 102 Measurement of Bond Strength of Gleeble Simulated Solid-State Welds (U)," SRT-MTS-93-4081, Westinghouse Savannah River Company, Aiken, SC, September 30, 1993. 
Table 1: Weld Interface Length Measurements and Approximate ASTM Grain Size Numbers from Photomicrographs. All Welds from Recommended Parameter Ranges (KS19 - CER6) Exhibited Interface Length Exceeding Minimum Requirement of $0.335^{\prime \prime}$. C1 or C2 Designates Coupon 1 or 2 from Each Sample. Plug Material (P) Grain Size was ASTM No. 5 and Canister Nozzle (N) Grain Size was ASTM No. 3.

\begin{tabular}{|c|c|c|c|c|}
\hline Sample & $\begin{array}{l}\text { Weld Length } \\
\text { (in.) }\end{array}$ & $\begin{array}{l}\text { Top Grain Size } \\
\text { (ASTM No.) }\end{array}$ & $\begin{array}{l}\text { Center Grain Size } \\
\text { (ASTM No.) }\end{array}$ & $\begin{array}{l}\text { Bottom Grain Size } \\
\text { (ASTM No.) }\end{array}$ \\
\hline KS01 C2 & 0.309 & 10(Plug) 3(Nozzle) & $\geq 10$ & 8(Plug) 6(Nozzle) \\
\hline $\mathrm{KSO2}$ C2 & 0.373 & 6 & 7 & 9 \\
\hline $\mathrm{KS} 03 \mathrm{C2}$ & 0.390 & 7 & 10 & $>10$ \\
\hline $\mathrm{KS} 04 \mathrm{C2}$ & 0.367 & 8 & 10 & $>10$ \\
\hline KS05 C1 & 0.382 & 6 & 9 & $>10$ \\
\hline KS06 C1 & 0.190 & 7 & 9 & 9 \\
\hline KS07 C2 & 0.429 & 7 & 8 & 10 \\
\hline KS08 C1 & 0.351 & 6 & 8 & 10 \\
\hline KS09 C1 & 0.373 & 6 & 8 & 10 \\
\hline KS19 C1 & 0.386 & 7 & 8 & 10 \\
\hline KS31 C2 & 0.400 & 7 & 9 & $>10$ \\
\hline KS33 C2 & 0.391 & 7 & 9 & $>10$ \\
\hline KS35 C1 & 0.427 & 7 & 10 & $>10$ \\
\hline KS37 C2 & 0.391 & 8 & 10 & $>10$ \\
\hline KS38 C2 & 0.392 & 8 & 10 & $>10$ \\
\hline $\mathrm{KS} 40 \mathrm{~A} \mathrm{C2}$ & 0.390 & 8 & 9 & $>10$ \\
\hline $\mathrm{KS} 41 \mathrm{C2}$ & 0.377 & 8 & 10 & $>10$ \\
\hline $\mathrm{KS} 42 \mathrm{C} 2$ & 0.420 & 8 & 9 & $>10$ \\
\hline KS44 C2 & 0.393 & 7 & 8 & 10 \\
\hline KS46 C1 & 0.397 & 7 & 8 & 10 \\
\hline CER2 C1 & 0.395 & 8 & $\boldsymbol{9}$ & $>10$ \\
\hline CER4 C2 & 0.391 & 8 & 9 & 10 \\
\hline CER6 C2 & 0.388 & 7 & 9 & $>10$ \\
\hline
\end{tabular}




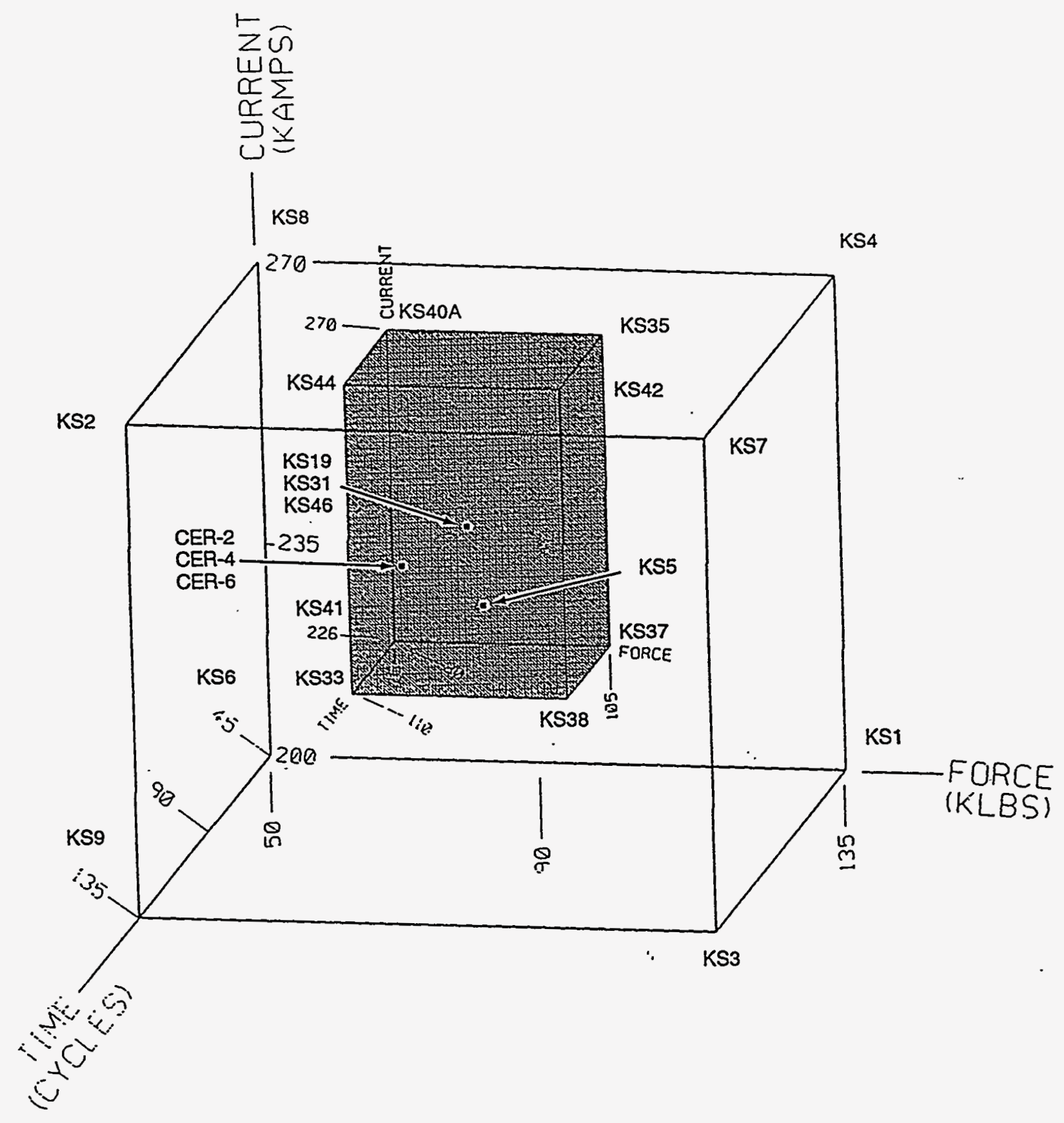

Figure 1: Relationship of Phase 1 Parameter Ranges. Initial Range, Parts A and B (Outer Cube - Welds KS01 to KS09) to Recommended Range, Part C (Dark Inner Cube - Welds KS19 - KS44) [2]. Sample Numbers Shown are Welds Selected for Characterization. 
Page 13
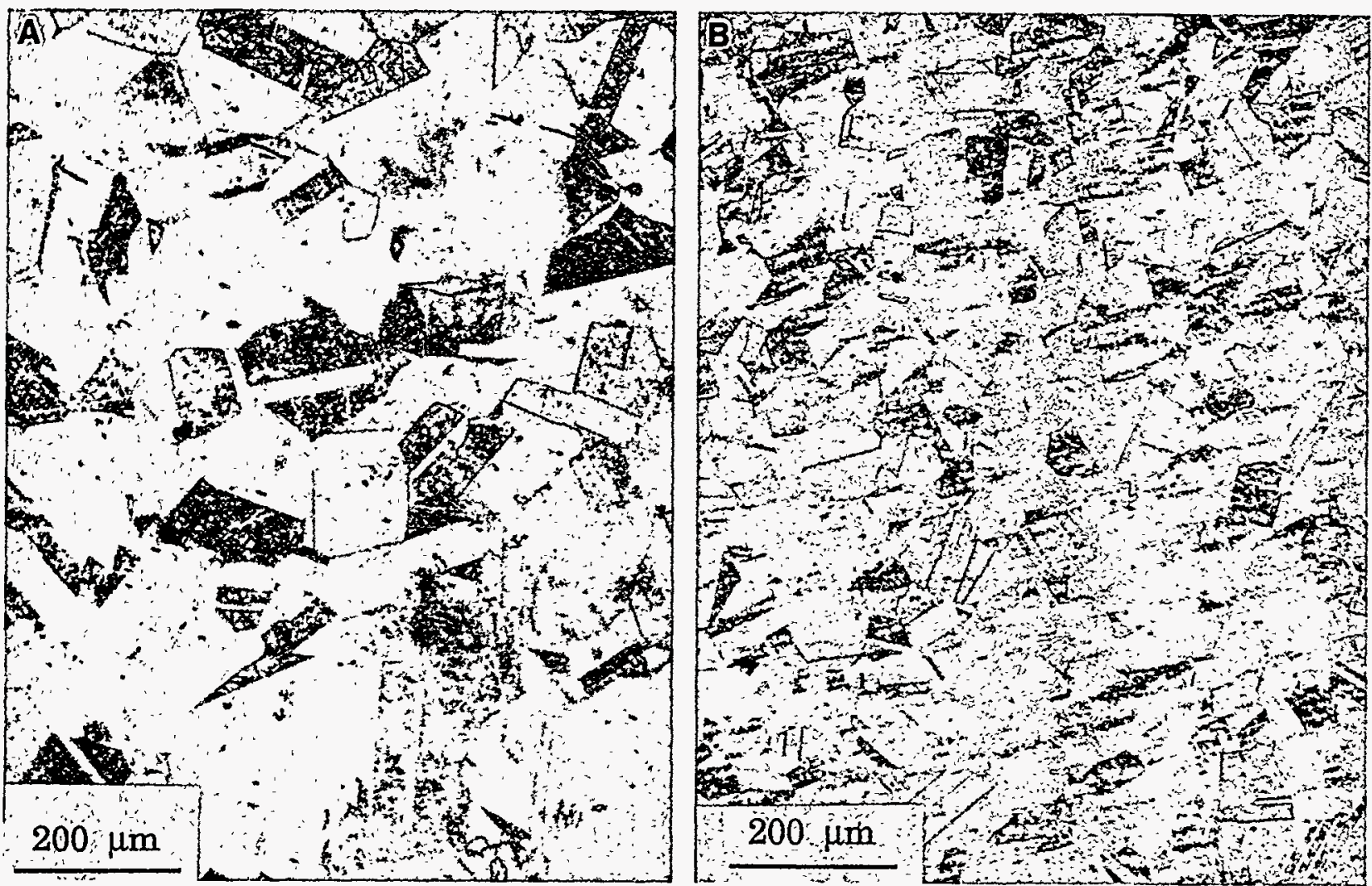

Figure 2: Canister Nozzle (A) and Plug (B) Base Metal Microstructures. ASTM Grain Size Numbers 3 (A) and 5 (B), Respectively. 
Page 14

A

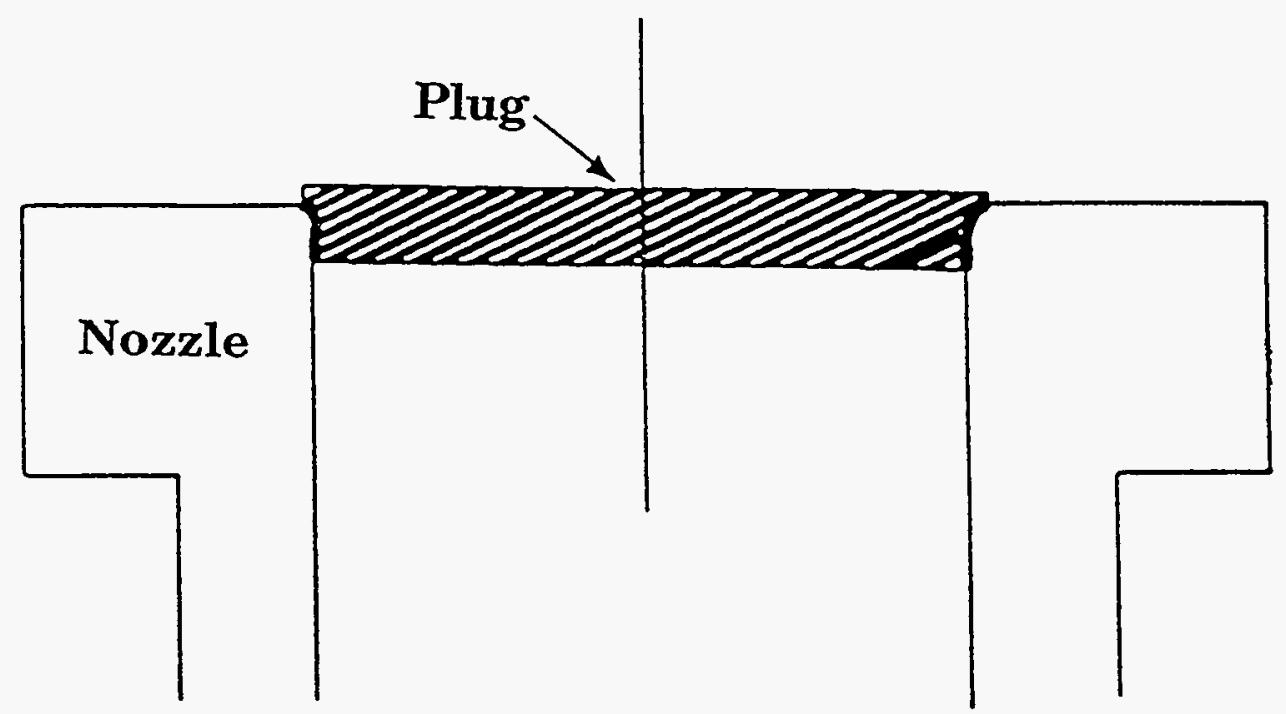

B

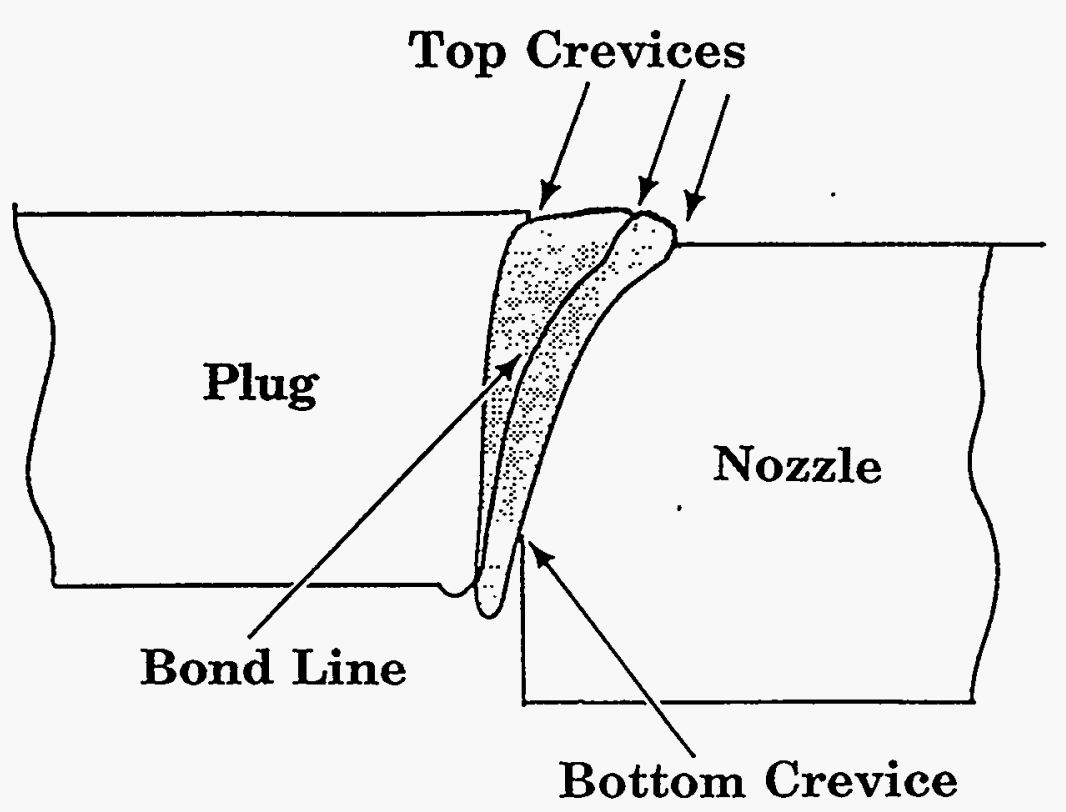

Figure 3: Schematic of Plug to Nozzle Resistance Upset Weld Cross Section(A) and Weld Bond Area (B). Note Interference Fit and Location of Crevices. Weld Interface Length Measured from Bottom Crevice to Closest Top Crevice. (Modified from [2].) 
Page 15
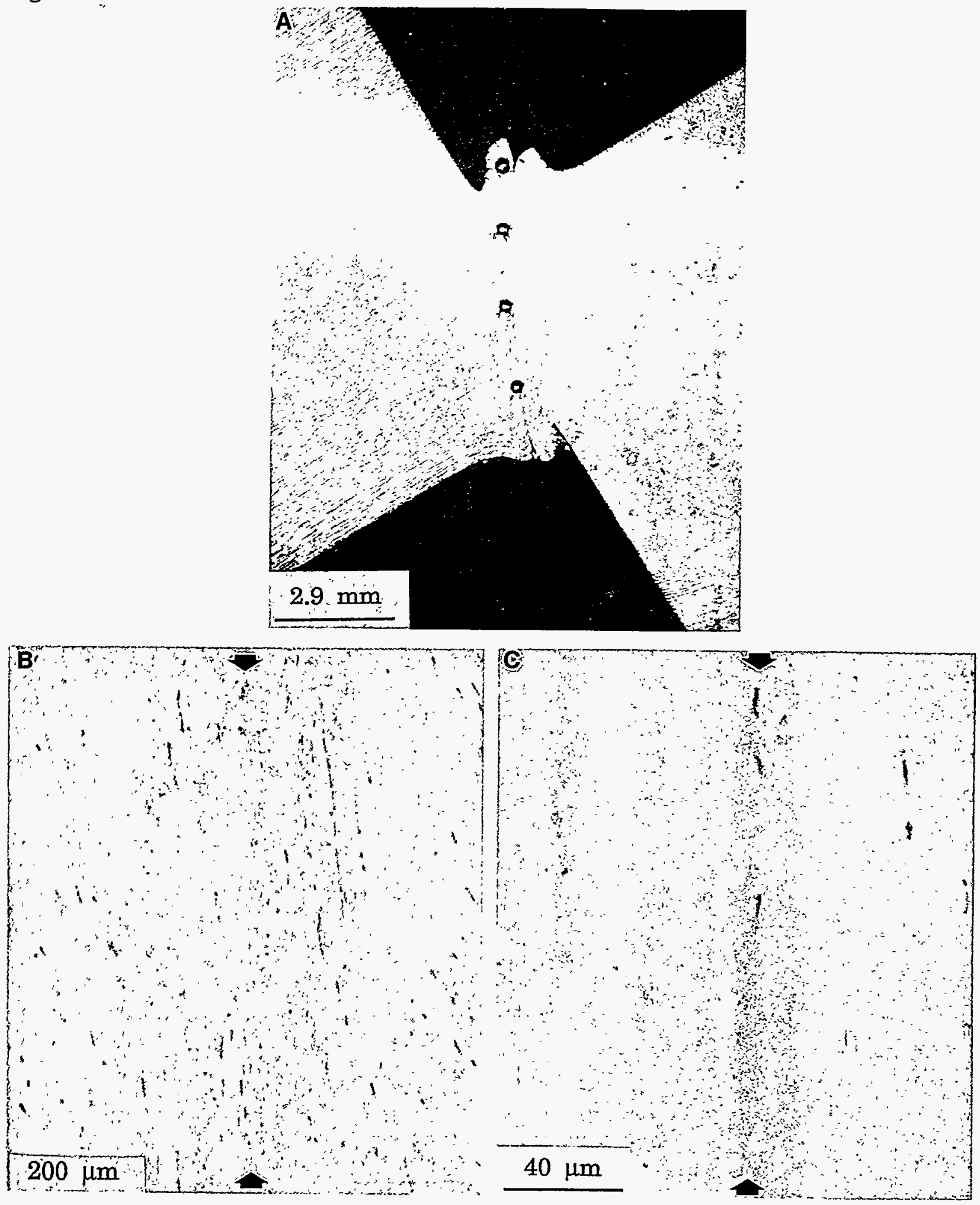

Figure 4: Sample KS06 Welded at Lowest Range of Parameters. Weld Cross Section (A) and Bond Line at Center (B,C). Note Relatively Good Bonding Indicated by Lack of Continuous Bond Line (Arrows). Indentations Present from Hardness Tests (A). Plug Material on Left in (A) and on Right in (B,C). Edges of Plug and Nozzle in (A) Indicate Interference Fit Prior to Welding. 
Page 16
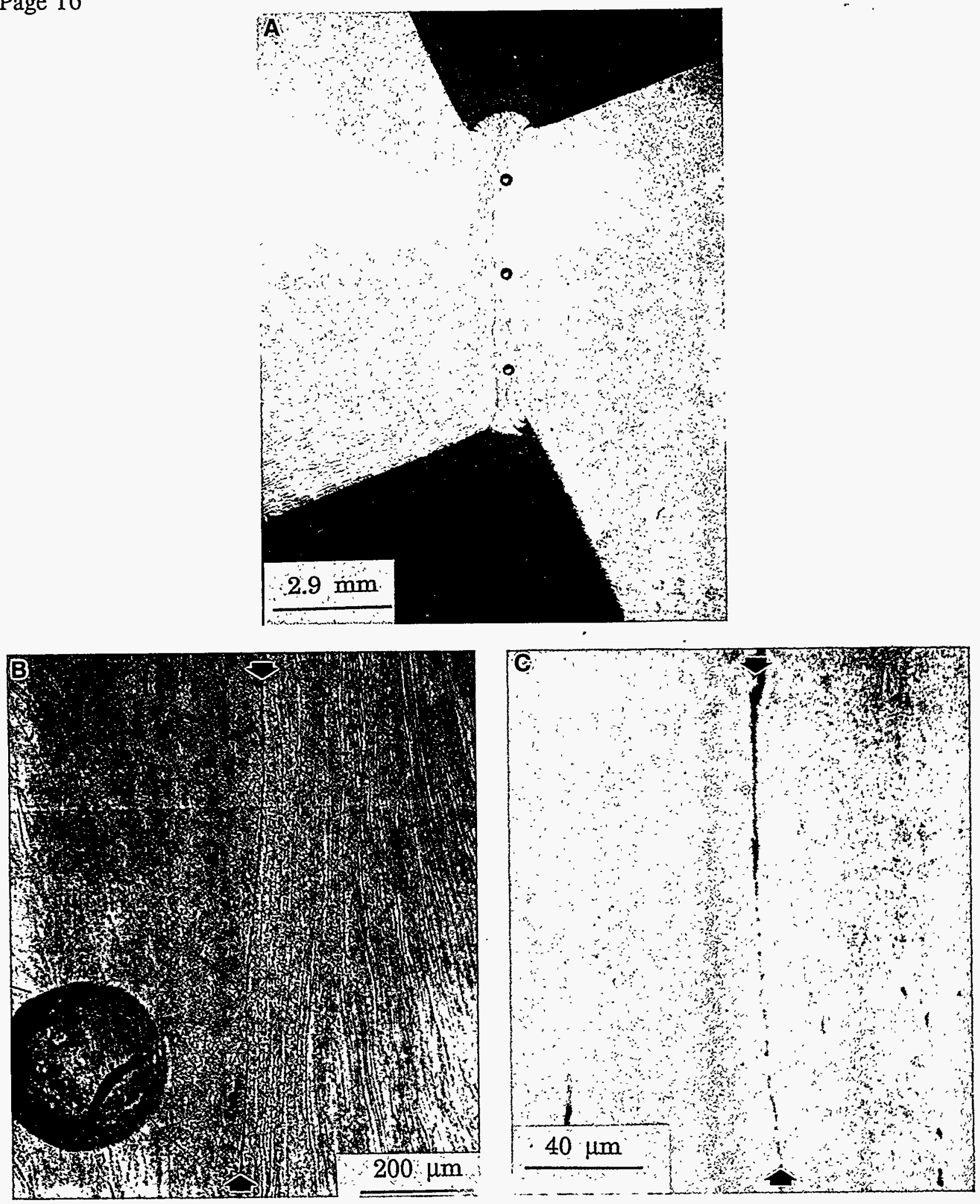

Figure 5: Sample KS01 Welded at High Force, Low Current and Time. Weld Cross Section (A) and Bond Line at Center (B,C). Note Intermittent Voids, Apparent Along Entire Length of Bond Line Shown. Plug Material on Left in (A) and on Right in (B,C). Indentations Present from Hardness Tests (A). 
Page 17
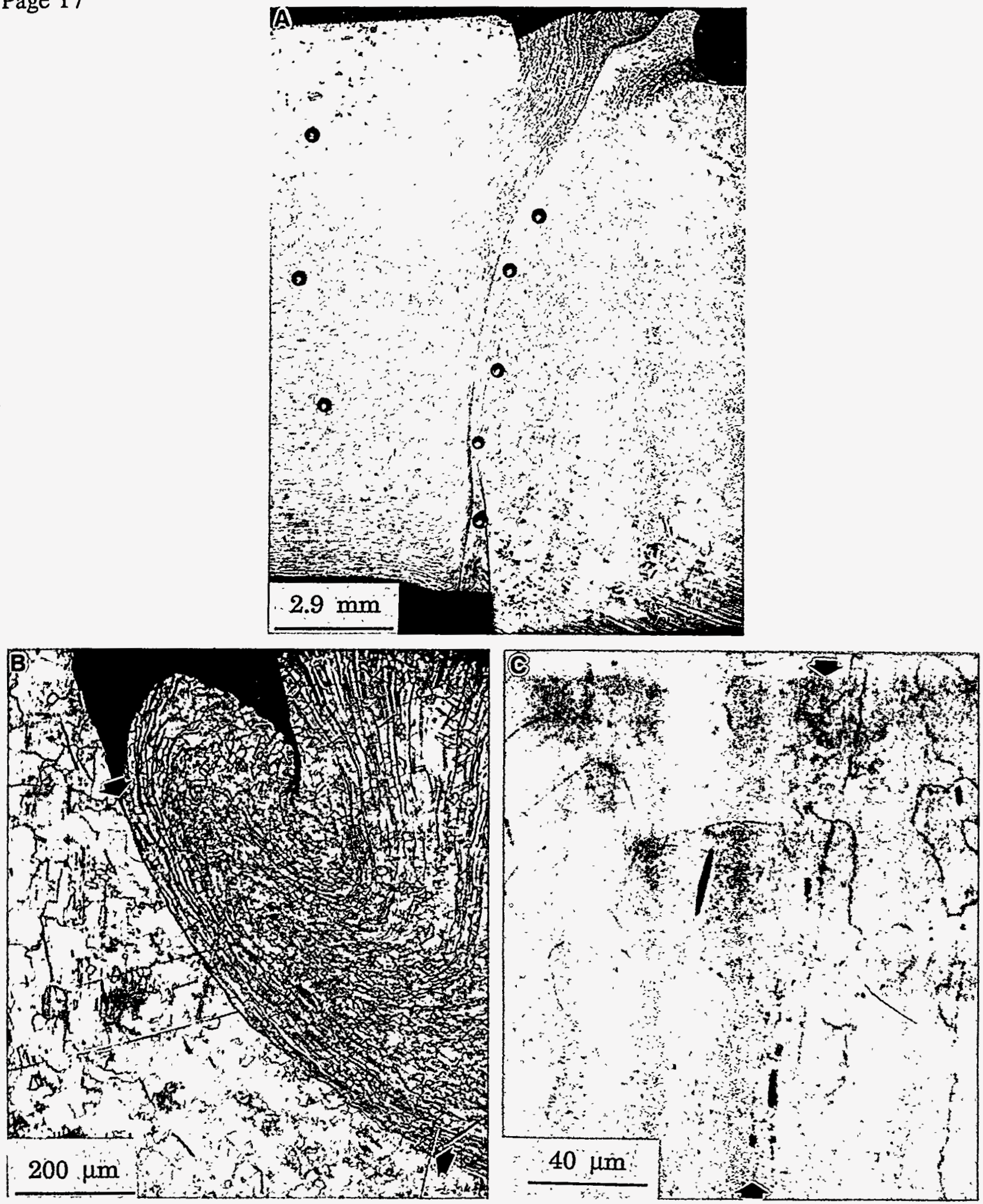

Figure 6: Sample KS05 Welded at Intermediate Parameter Settings (Initial Parameter Space). Weld Cross Section (A) and Bond Line at Top (B,C), Center $(\mathrm{D}, \mathrm{E})$ and Bottom $(\mathrm{F}, \mathrm{G})$. Note Solid Bond Line (Indicated by Arrows) and Change in Grain Size Along Weld. Plug Material on Left in (A) and on Right in (B - G). Indentations Present from Hardness Tests (A). 
Page 18
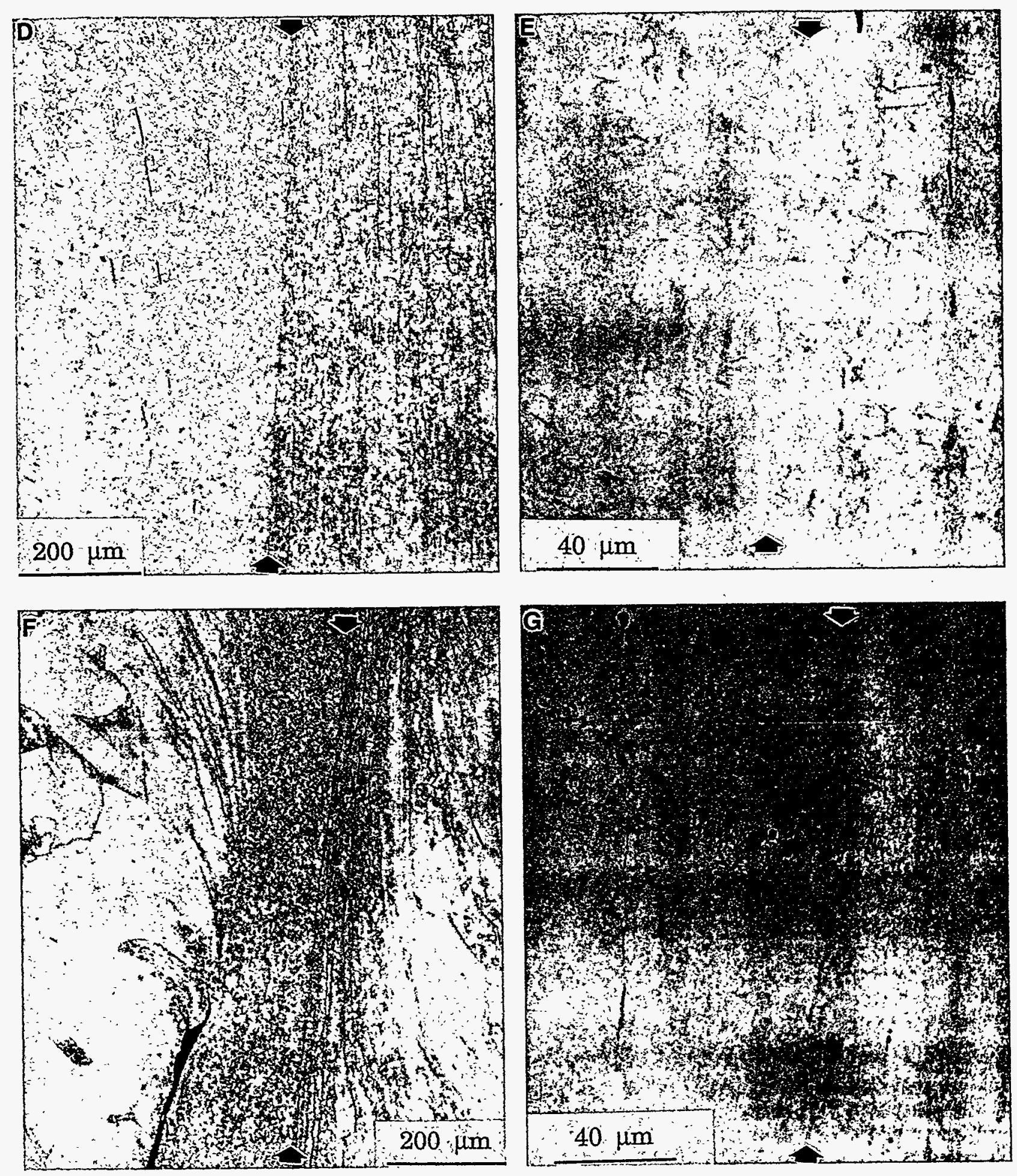

Figure 6: Continued 
Page 19

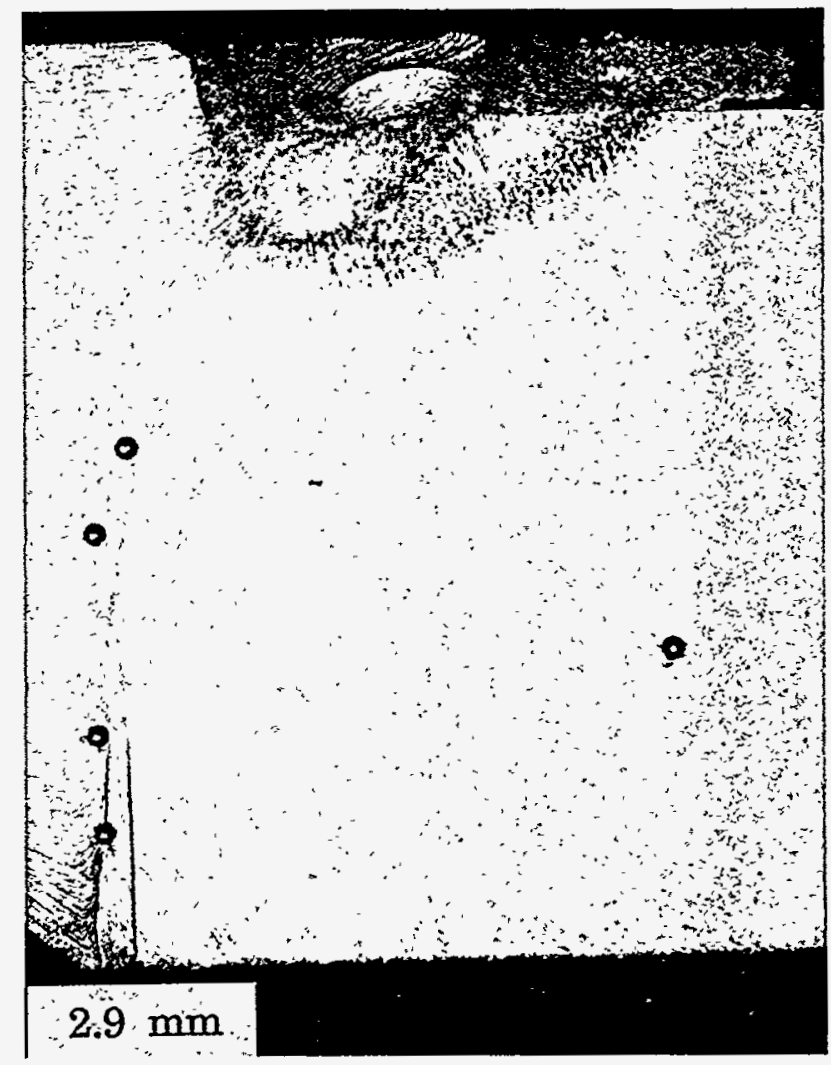

Figure 7: Sample KS02 Welded at High Current and Time, Low Force. Note Significant Melting at Top. Plug Material on Left. Indentations Present from Hardness Tests. 
Page 20

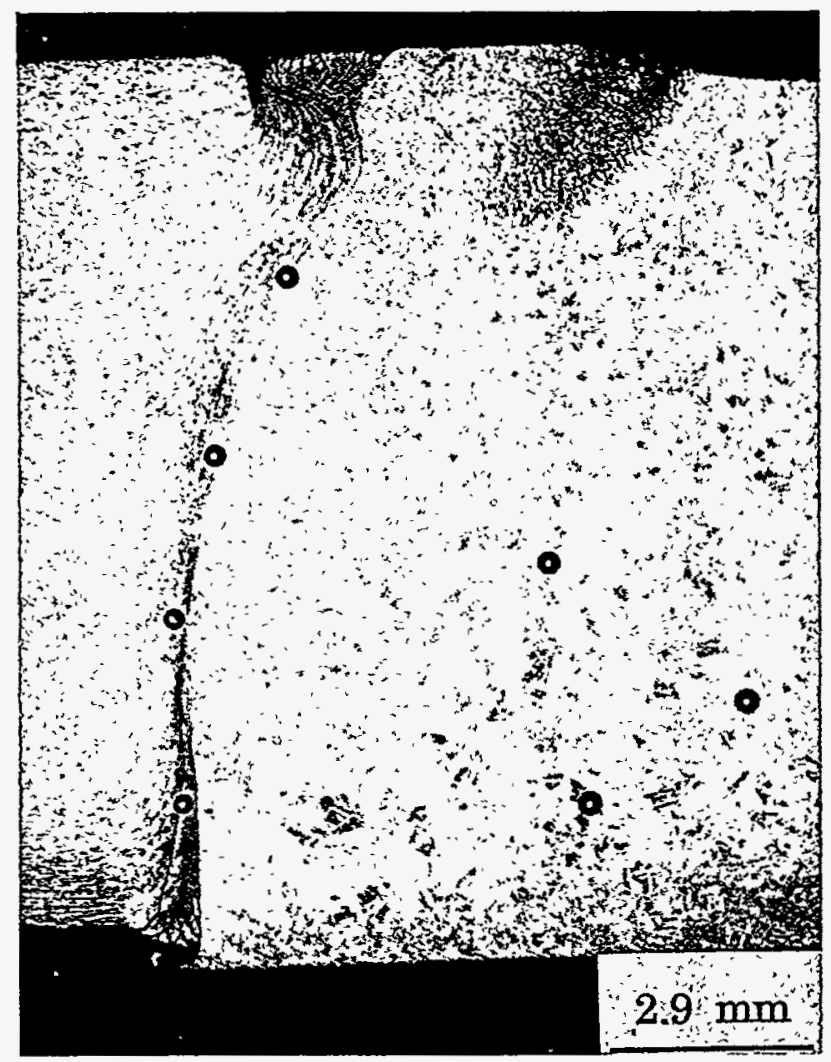

Figure 8: Sample KS07 Welded at High Current, Time and Force. Note Significant Melting at Top Eliminated Relative to KS02. Plug Material on Left. Indentations Present from Hardness Tests. 
Page 21
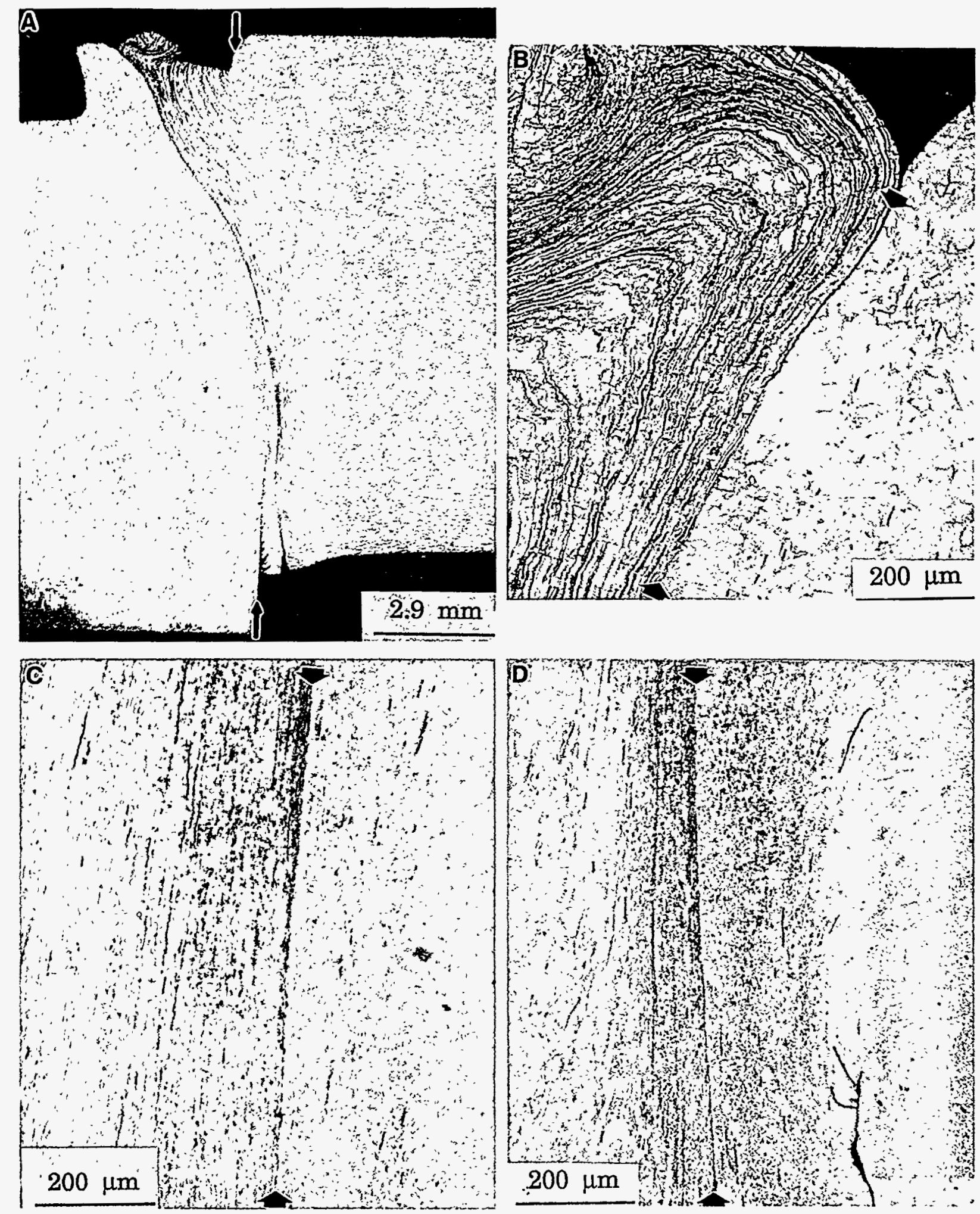

Figure 9: Sample KS41 Welded at Minimum Recommended Force, Current and Time (A). Adequate Bonding Observed at Top (B) Center (C) and Bottom (D). Plug Material on Right in (A) and on Left in (B,C,D). Arrows in (A) Show Original Position of Edges of Plug and Nozzle Which Indicate Interference Fit. 
Page 22
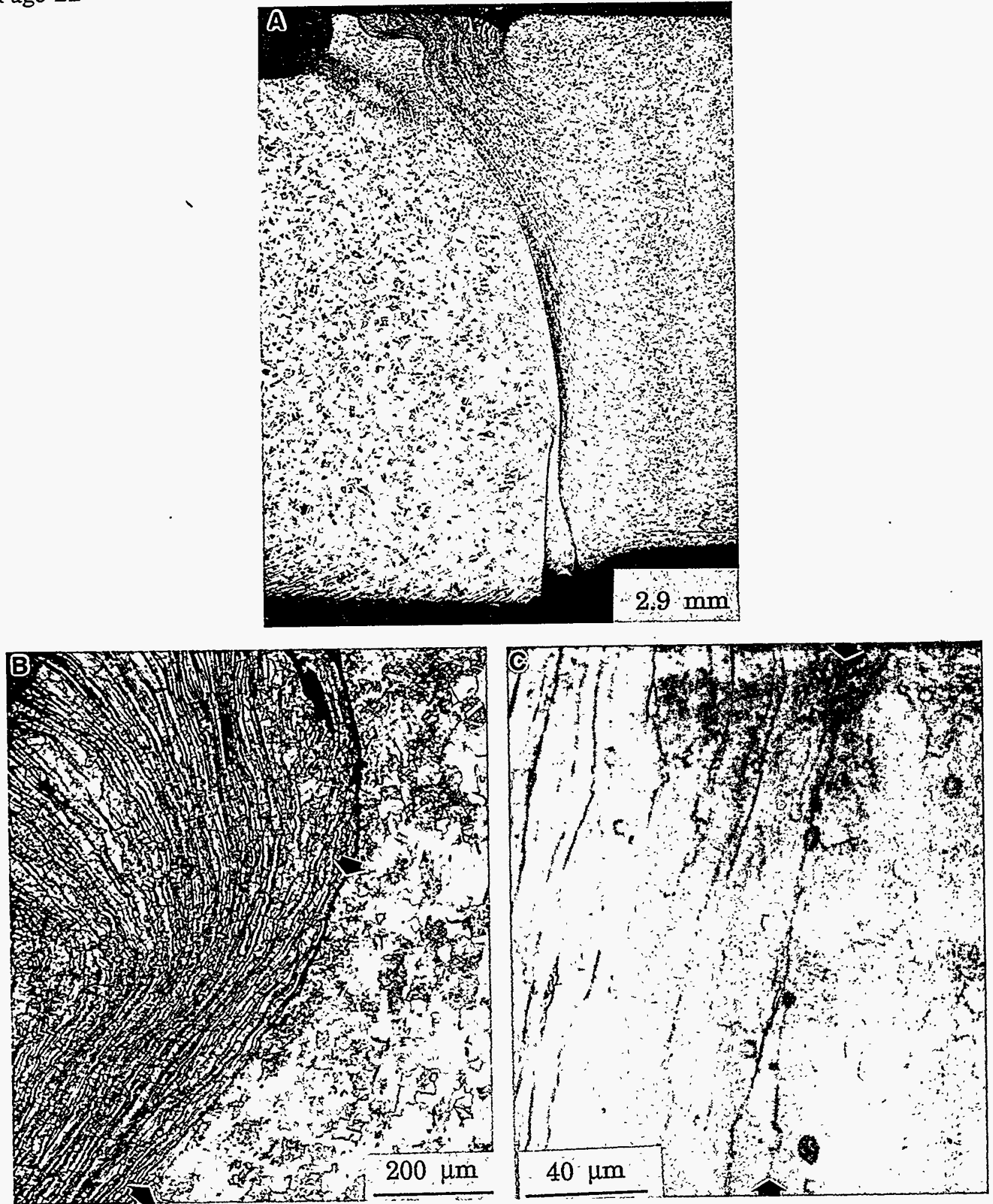

Figure 10: Sample KS19 Welded at Intermediate Force, Current and Time (Central position of Recommended Parameter Space). Weld Cross Section (A) and Bond Line at Top (B,C), Center (D, E) and Bottom (F,G). Note Solid Bond Line (Indicated by Arrows) and Change in Grain Size Along Weld. Plug Material on Right in (A) and on Left in (B - G). 


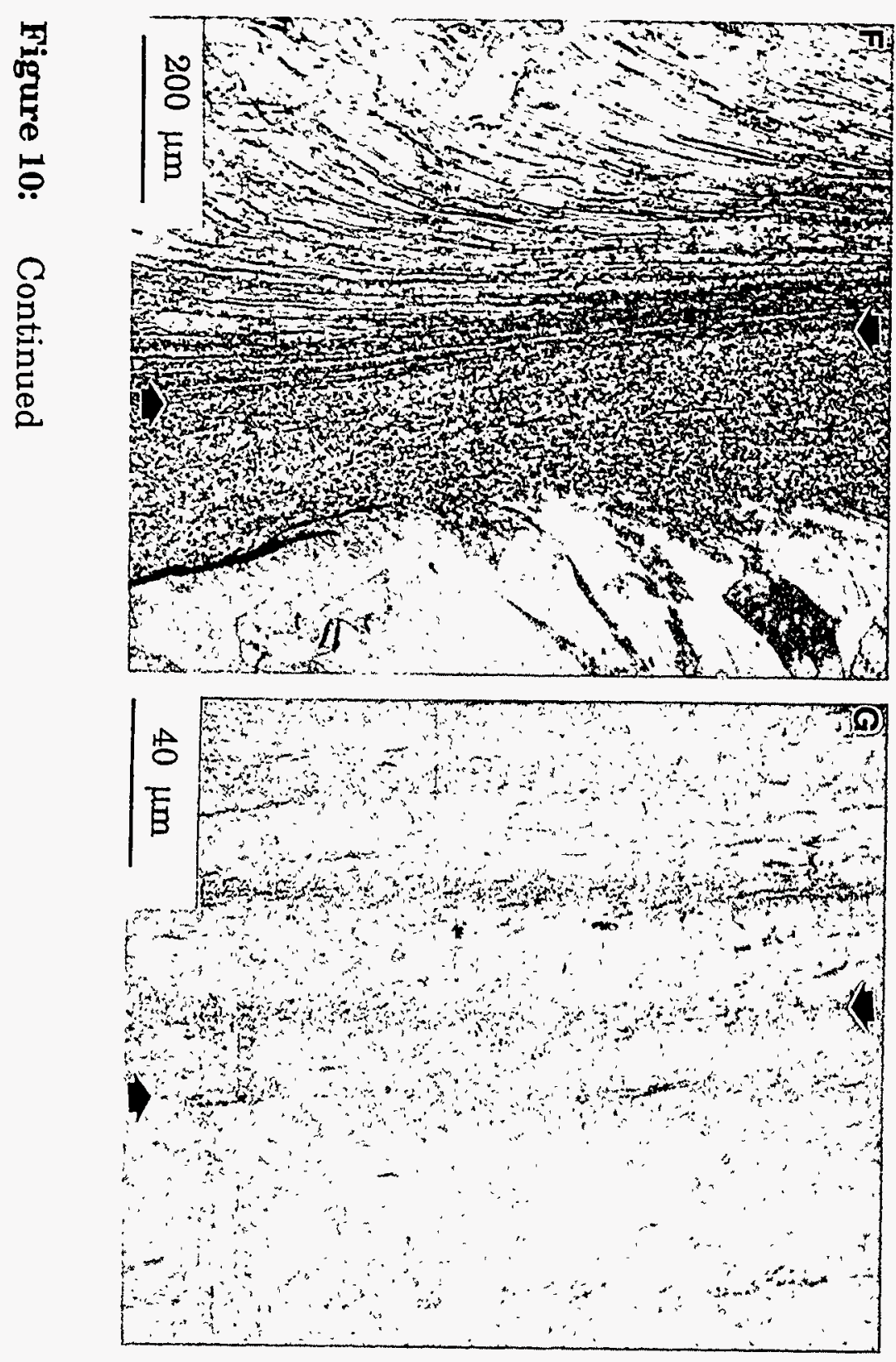

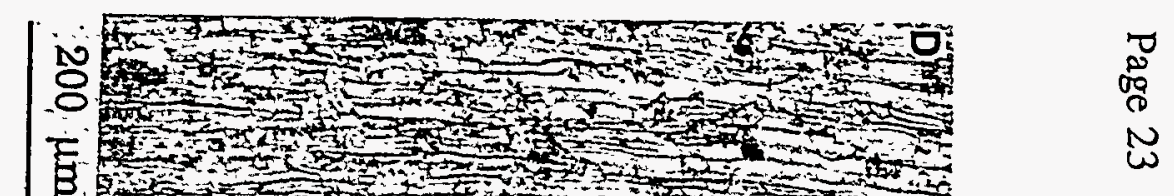

P

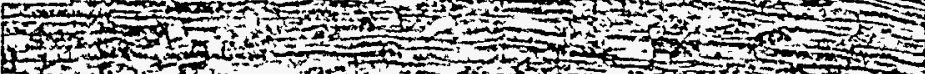

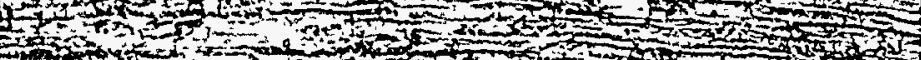

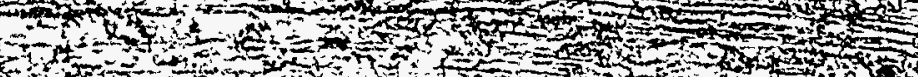

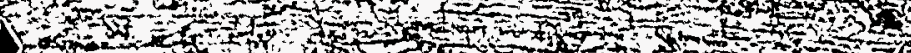

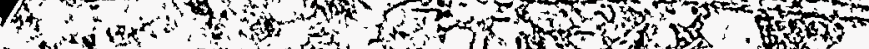

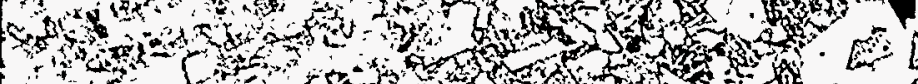

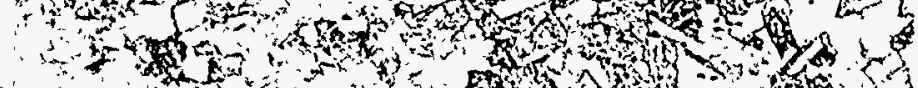

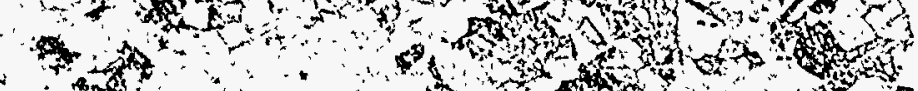

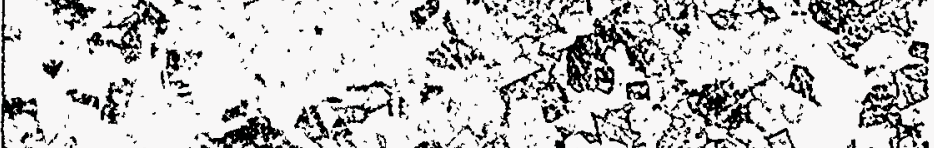

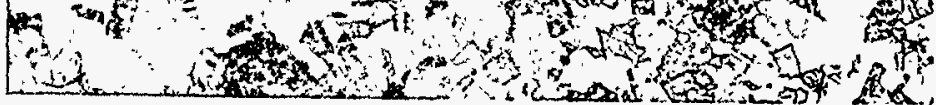

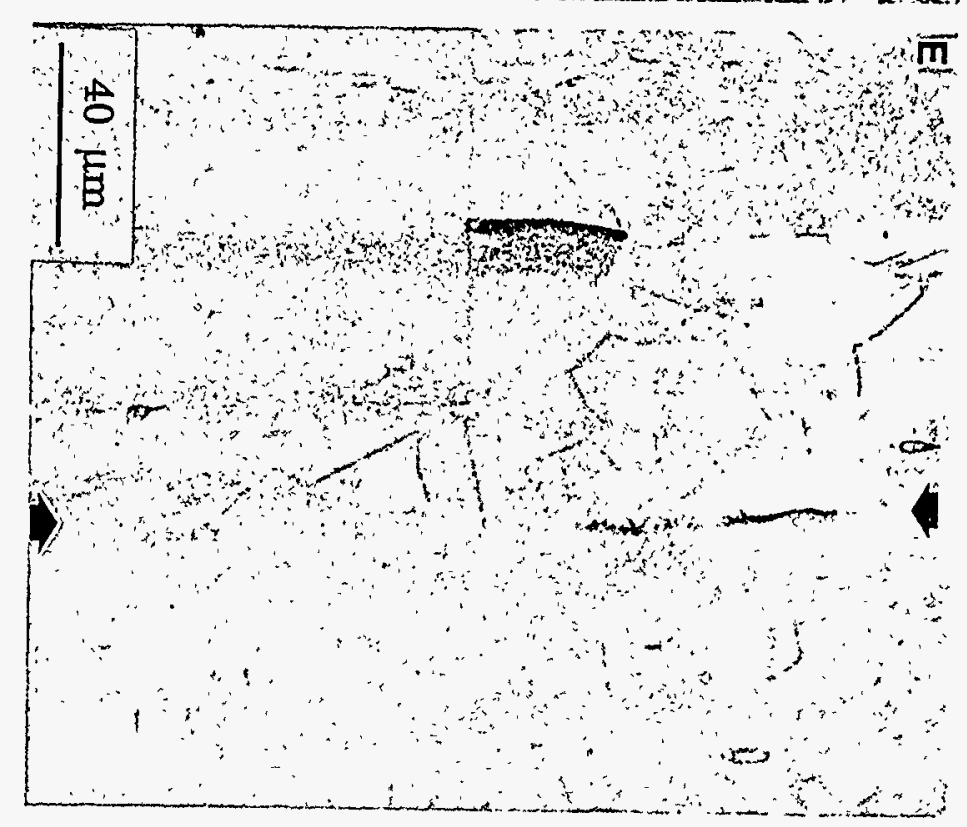


Page 24

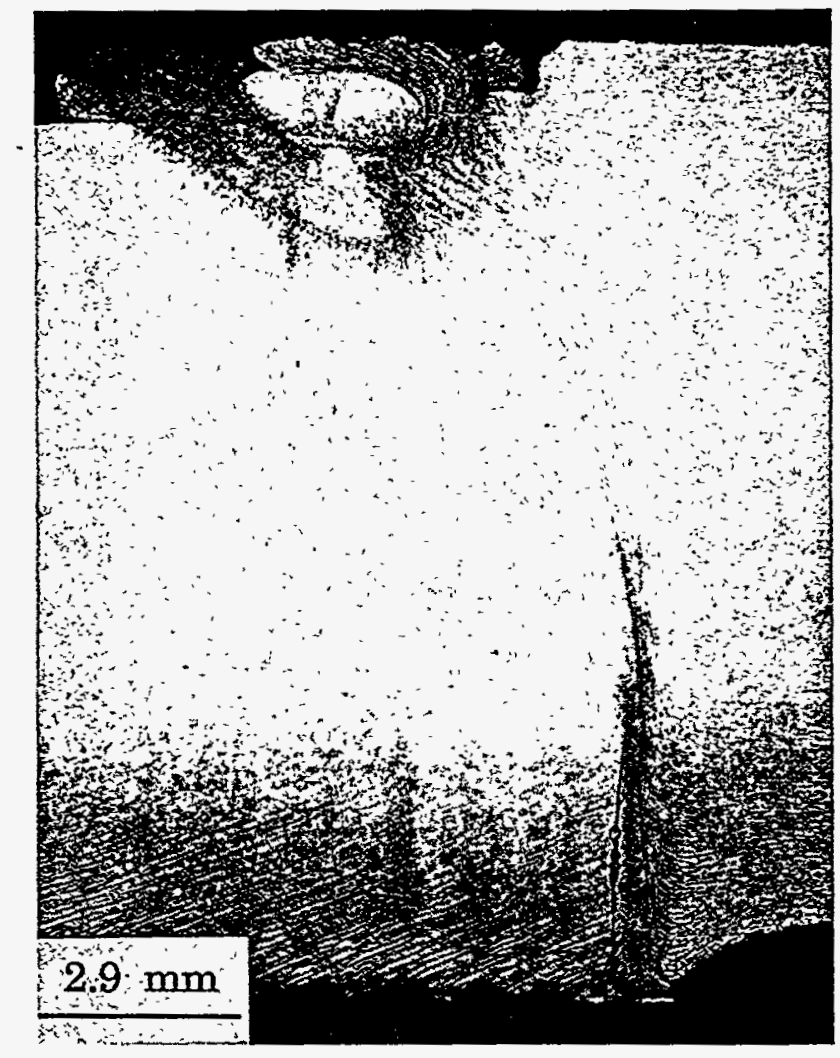

Figure 11: Sample KS44 Welded at Maximum Recommended Current, Time and Low Force. Note Significant Melting at Top. 
Page 25
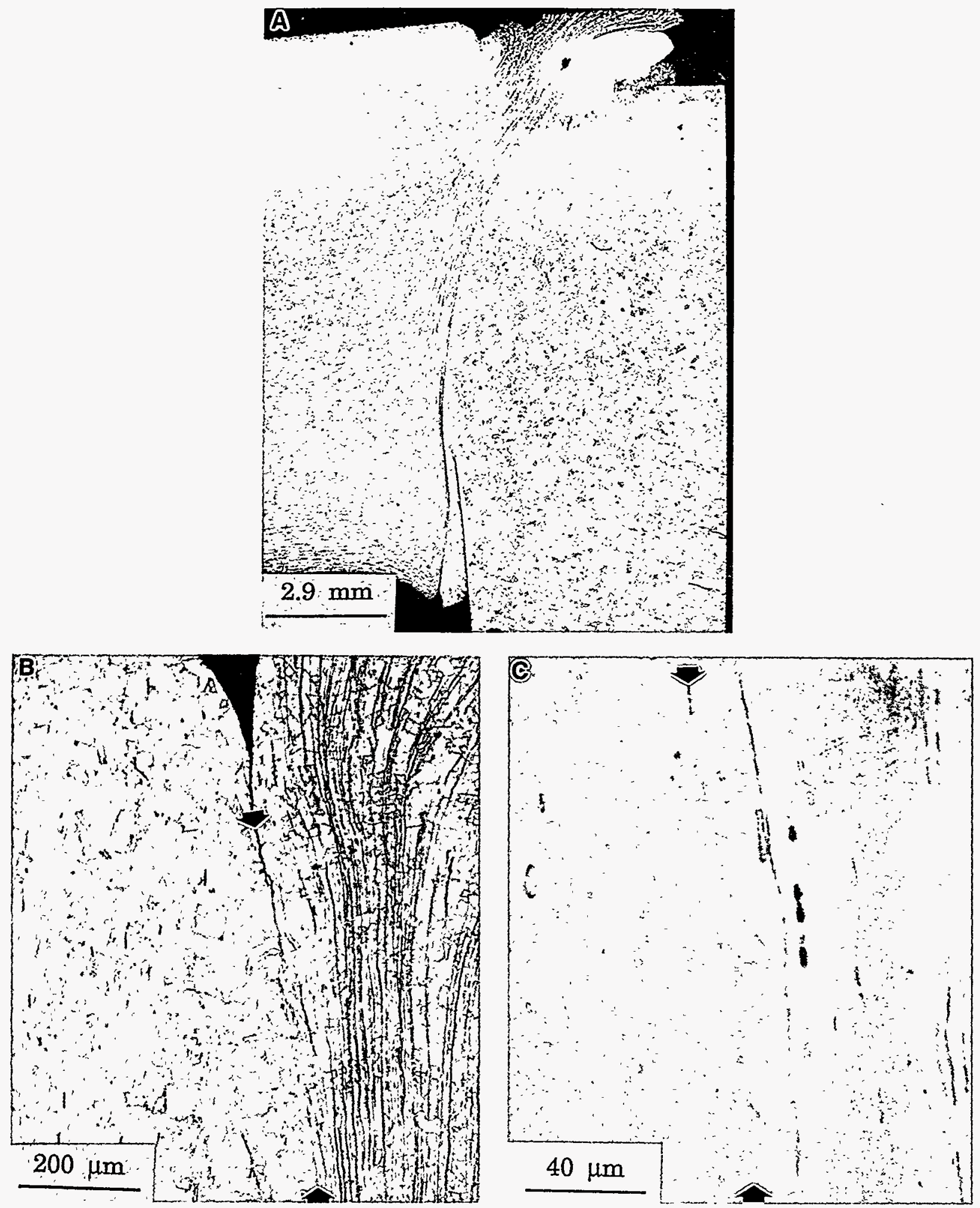

Figure 12: Sample CER-2 Welded at Slightly Less Than Intermediate Parameter Settings. Weld Cross Section (A) and Bond Line at Top (B,C), Center (D, E) and Bottom (F,G). Note Solid Bond Line (Indicated by Arrows) and Minimal Melting at Top. Plug Material on Left in (A) and on Right in (B - G). 

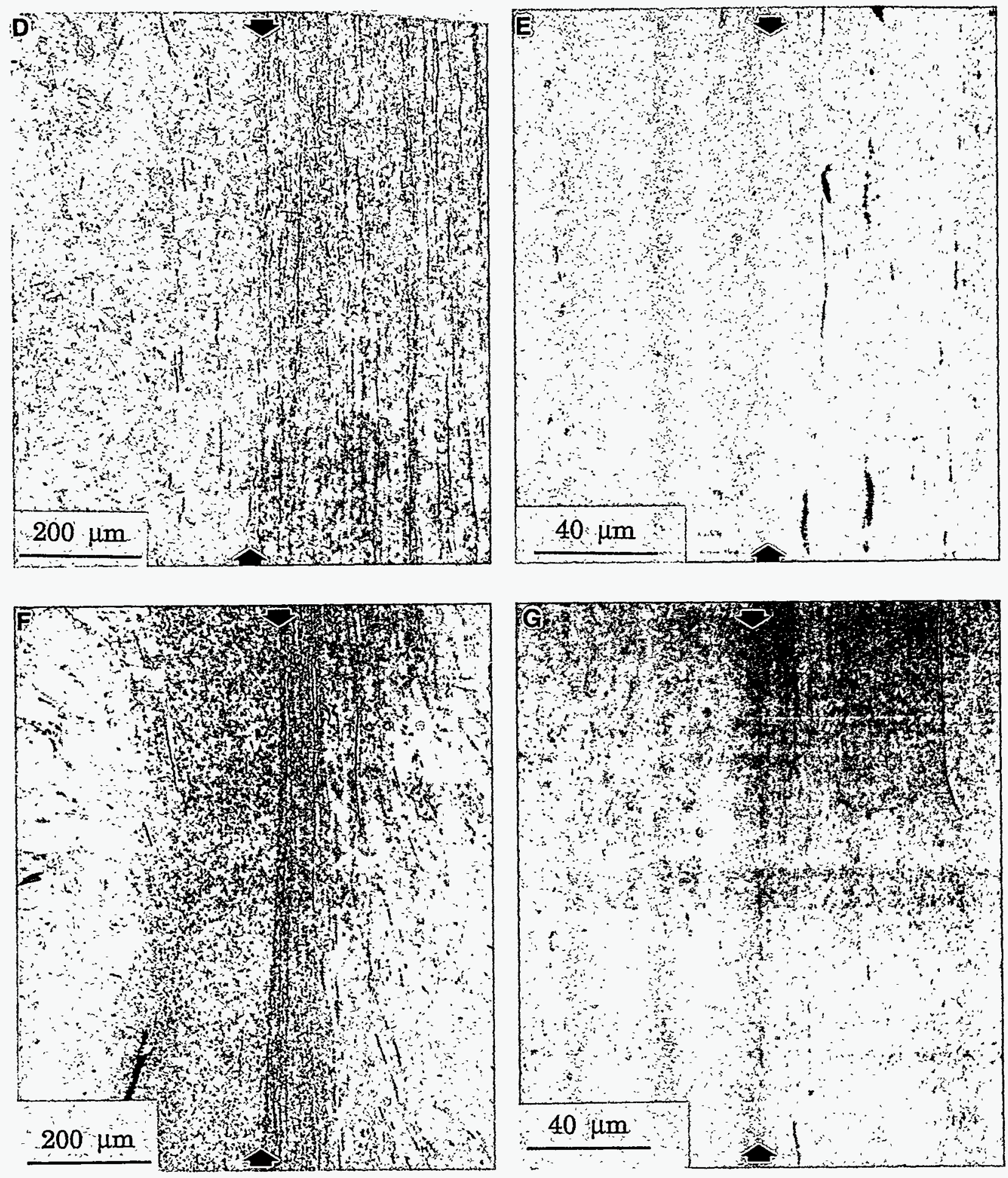

Figure 12: Continued 


\title{
Characterization of Type 304L Stainless Steel Solid-State Closure Welds for Radioactive Waste Containment
}

\author{
S. L. West
}

WESTINGHOUSE

SAVANNAH RIVER COMPANY

(1. Materialstechnology" 


\section{DWPF Canisters}

- Fabricated from Type 304L Stainless Steel

- Diameter: $2 \mathrm{ft}$

- Height: 9 ft, 10 in

- Wall Thickness: $0.375^{\prime \prime}$

- Sealed by Resistance Upset Welding

- 5" Diameter Plug, 0.5" Thick

- Interim Storage at SRS

- Integrity. Essential 


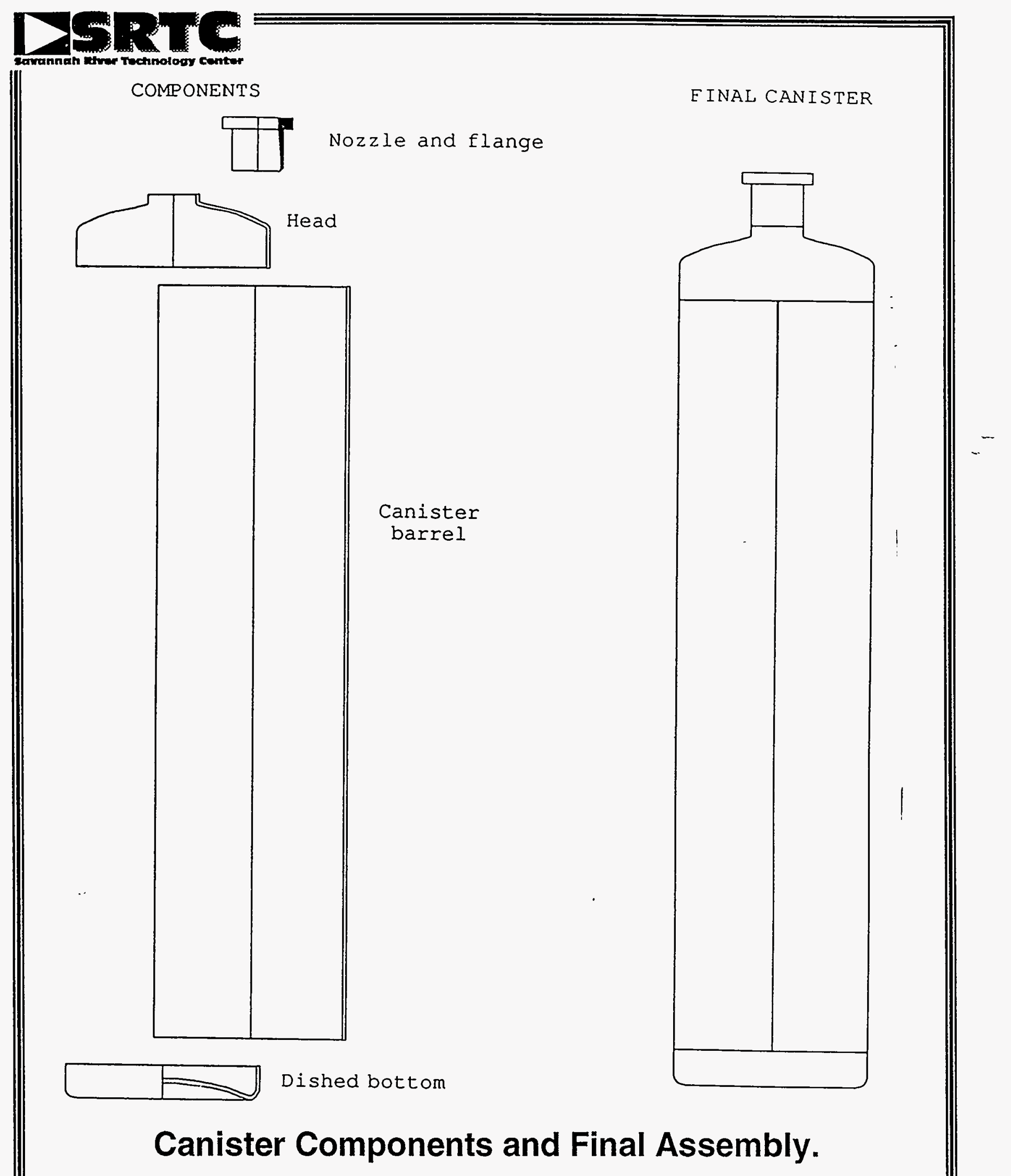

Nozzle and

Savannah River Technology Center Materials Technology Section 


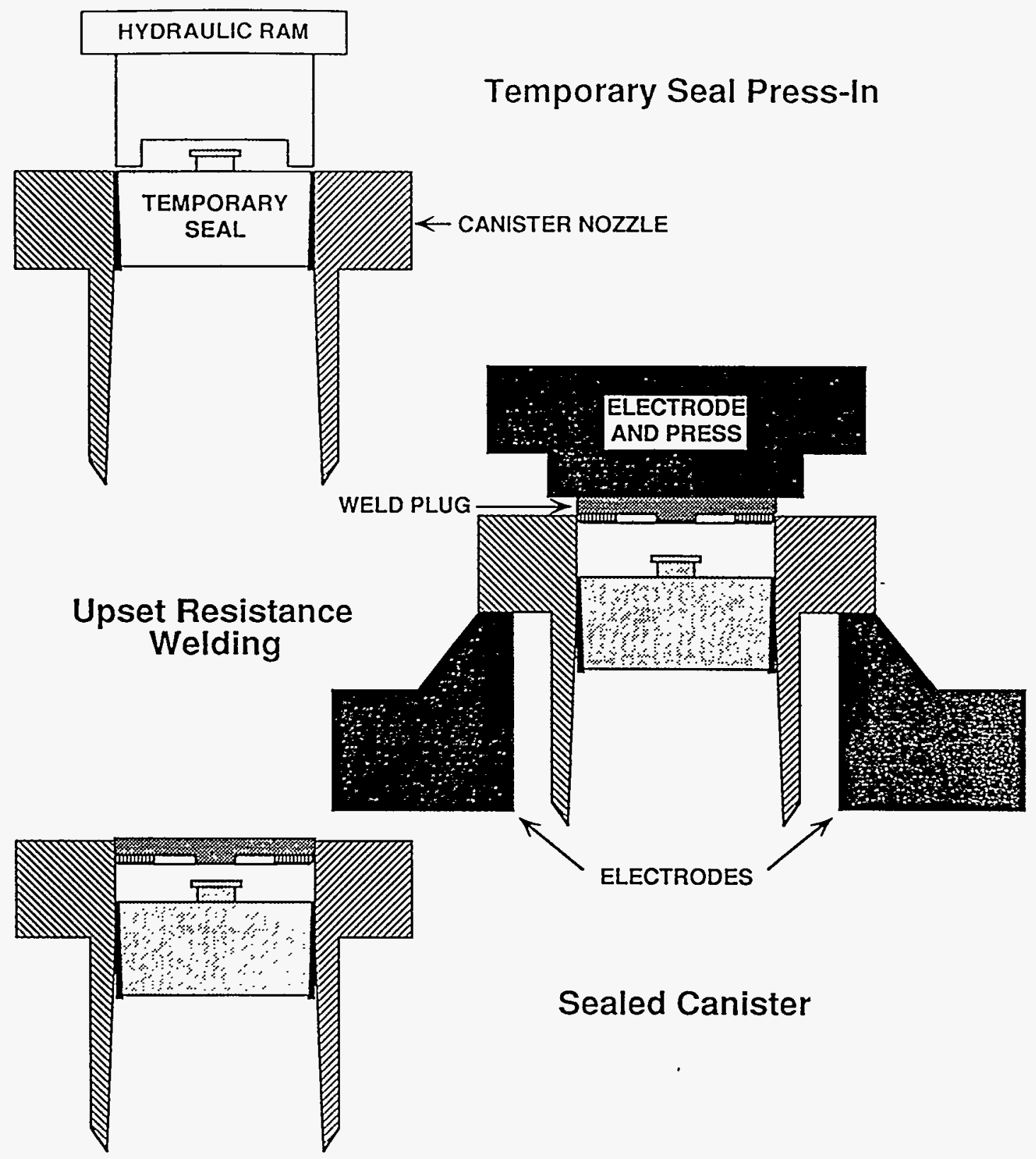

Resistance Upset Welding of Canister. 


\section{Resistance Upset Welding}

- Variables are Current, Force, Time

- Plastic Flow at High Temperature Joins Materials

- Fast, Reliable , r mel $\xi_{7}$

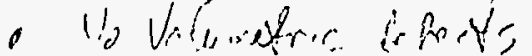

- Ideal for DWPF: Automation and Remote Operation 


\section{Canister Closure Weld Parametric Study}

- Requirements

- Parameter Range Allowing Variability

- Gas Tight Seal Weld

- Tensile Strength $\geq 304 \mathrm{~L}$

- Burst Strength $\geq$ Canister Burst Strength

- Bend Test/Fracture Test

- Metallographic Analysis - Zero Flaws, Bond Length $\geq 0.335^{\prime \prime}$

- Results ILentifieda

- Phase 1 - Recommended Parameter Envelope (Force, Current, Time)

- Phase 2 (Future) - 100 Qualification Welds During Cold Runs Ji, ir onin bisesessed

- DWPF JTG Review

- Document Weld Microstructures 


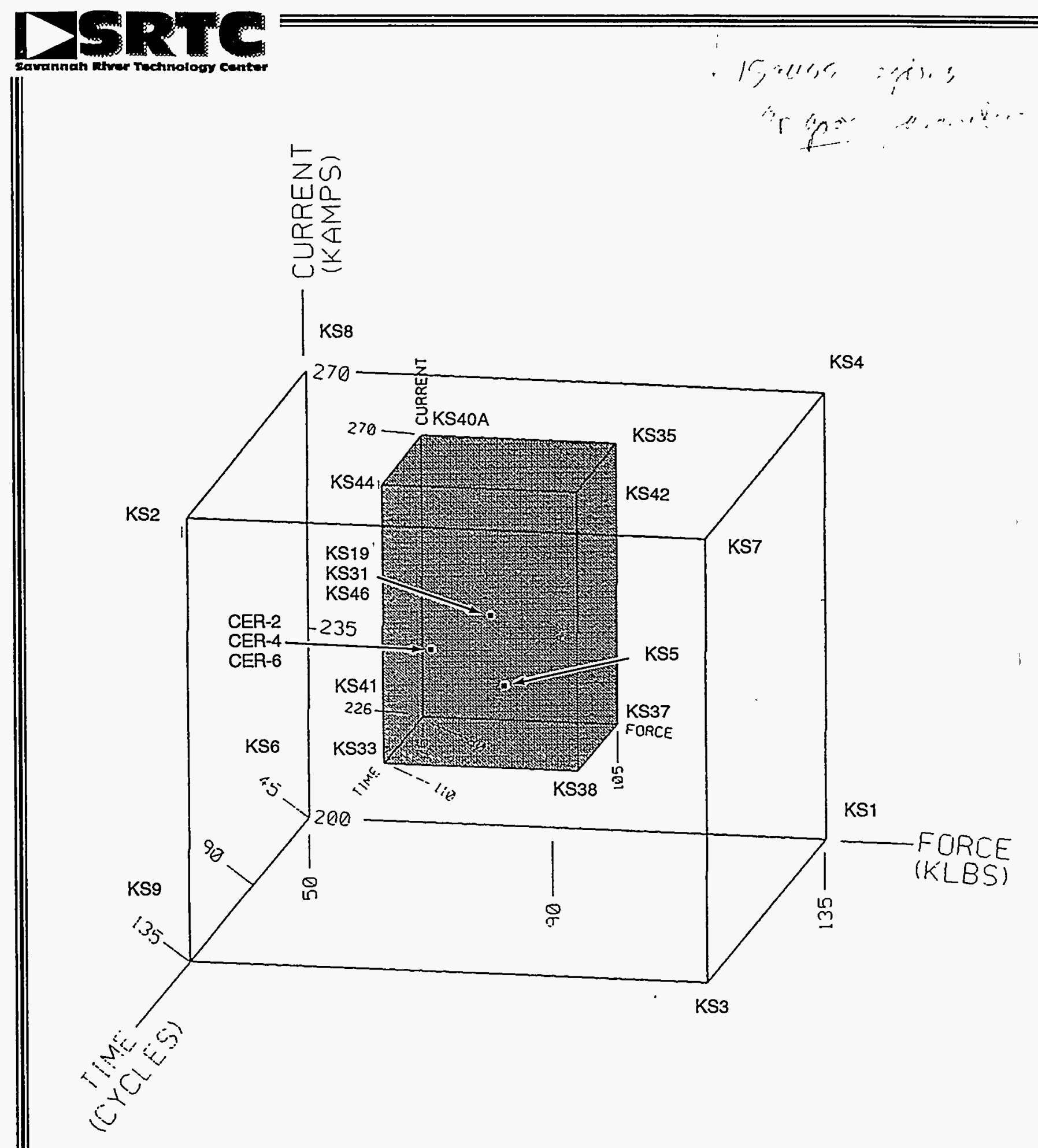

\section{Range of Parameters from Parametric Study. Large Open Cube - Initial Range Investigated, Smaller Shaded Box - Recommended Parameters.}




\section{Objectives}

- Document Microstructural Analysis

- Identify Relationships Among Microstructure, Welding Variables and Mechanical Properties

- Identify Effect of Parameter Shift on Microstructure -

- Provide Baseline Weld Microstructures for Future Corrosion/Characterization Studies 


\section{Approach}

- Select Samples to Include Extremes in Parameters (54 Samples Available)

- Optical Microscopy ( 7X to 500X)

- Examine Weld Interface Between Crevices 

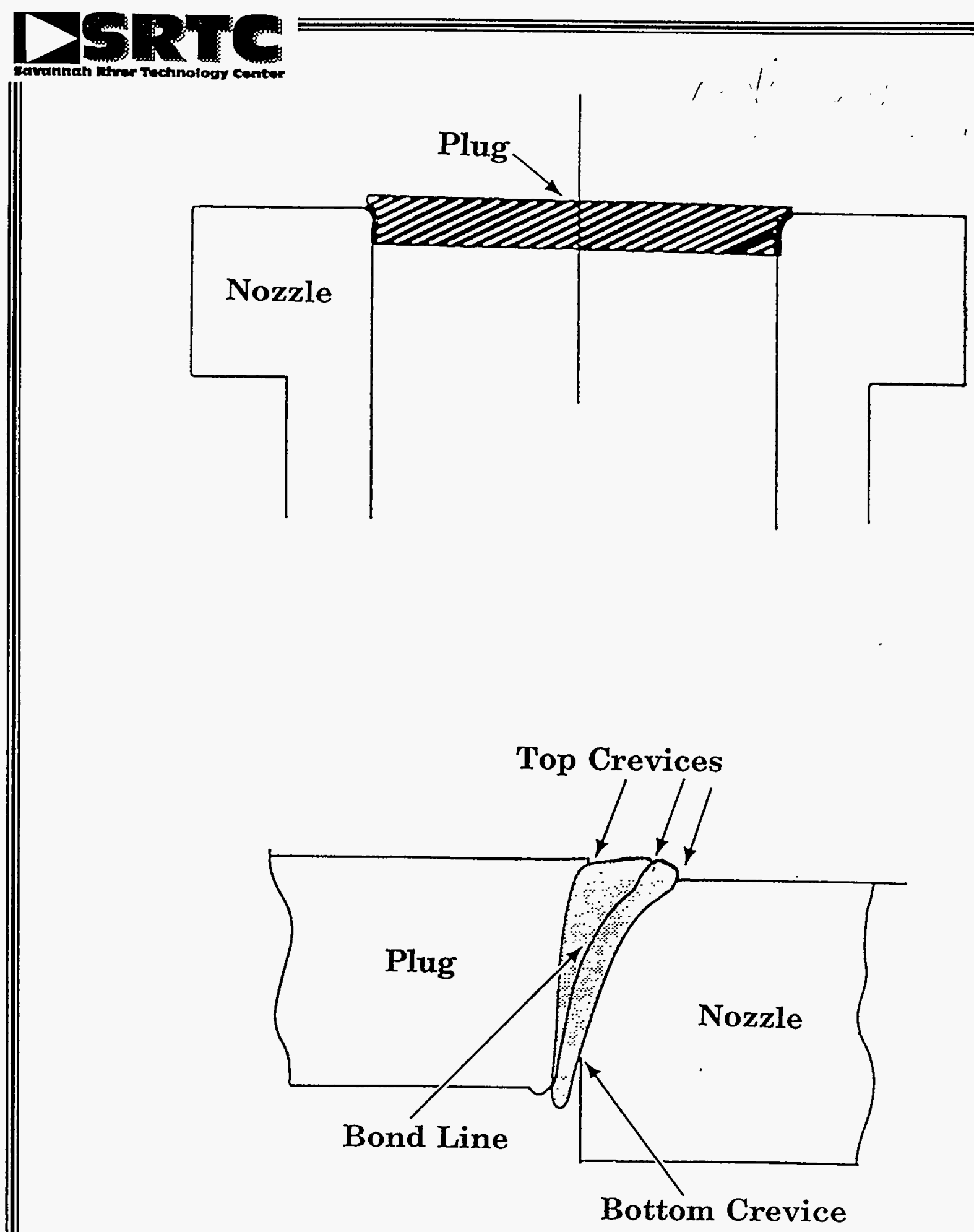

Schematic Of Plug to Nozzle Resistance Upset Weld Cross Section and Weld Bond Area 


\section{Results}

- Little Evidence of Poor Bond Quality

- Weld Microstructures Varied Significantly from Base Metal and Along Weld Interface

- Most Obvious Difference Among "Good" Welds was Degree of Melting at Interface 

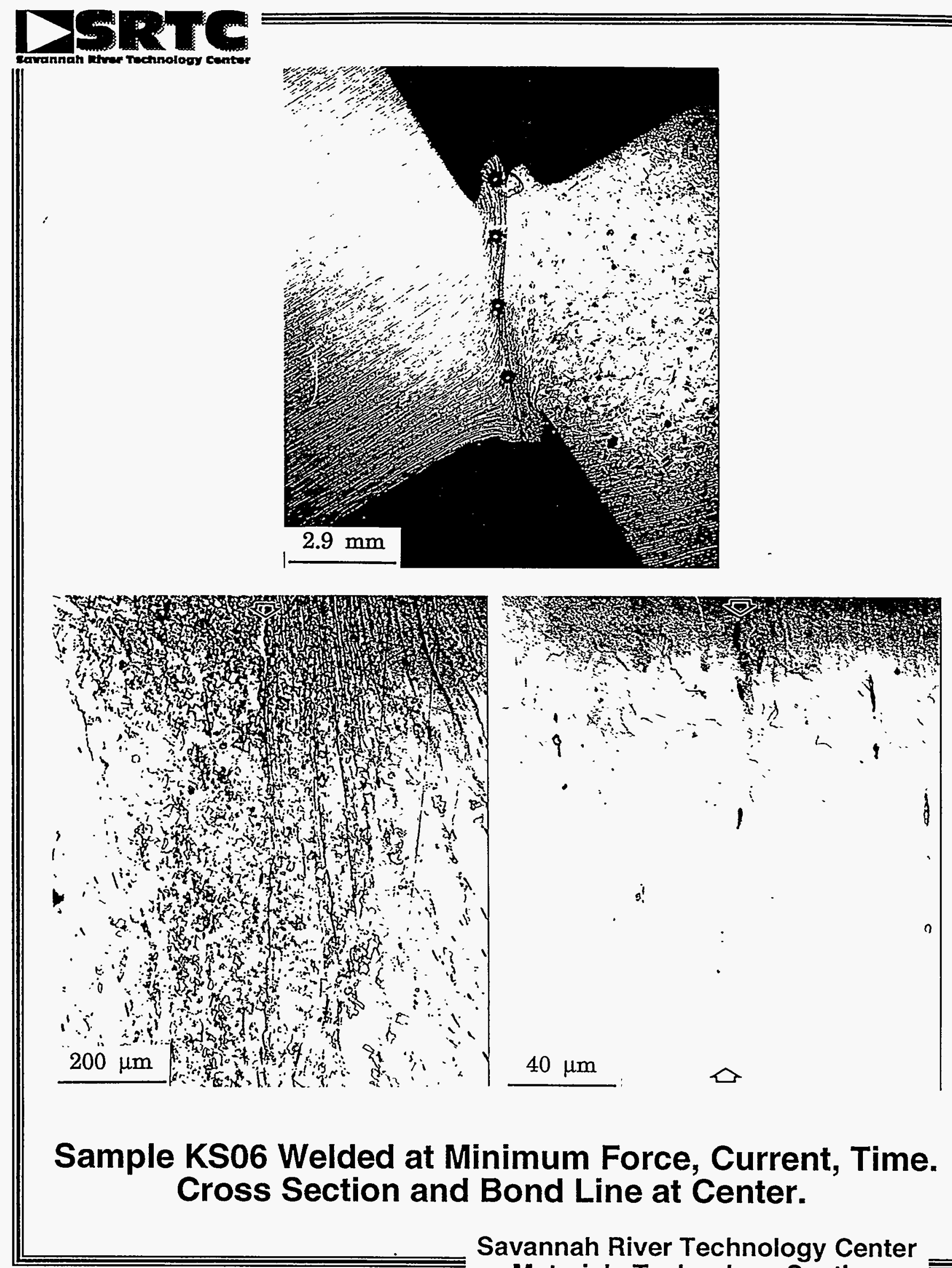

\section{Sample KS06 Welded at Minimum Force, Current, Time. Cross Section and Bond Line at Center.}

Savannah River Technology Center Materials Technology Section 

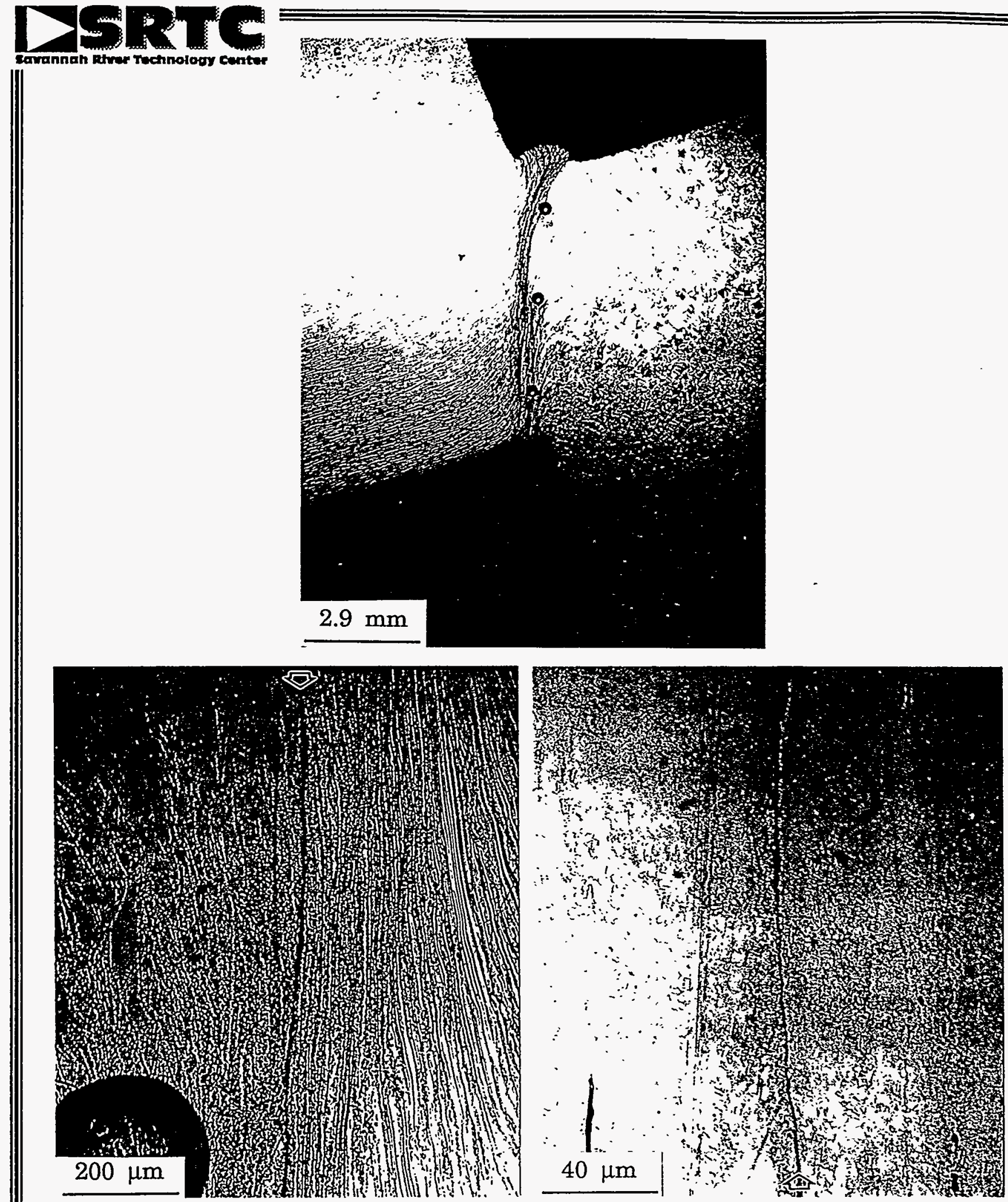

\section{Sample KS01 Welded at High Force, Low Current and Time. Cross Section and Bond Line at Center.}




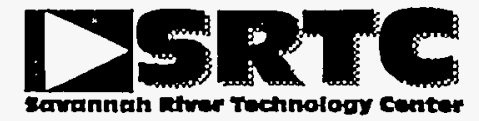

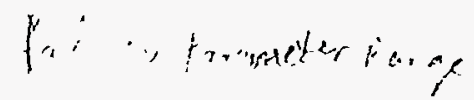
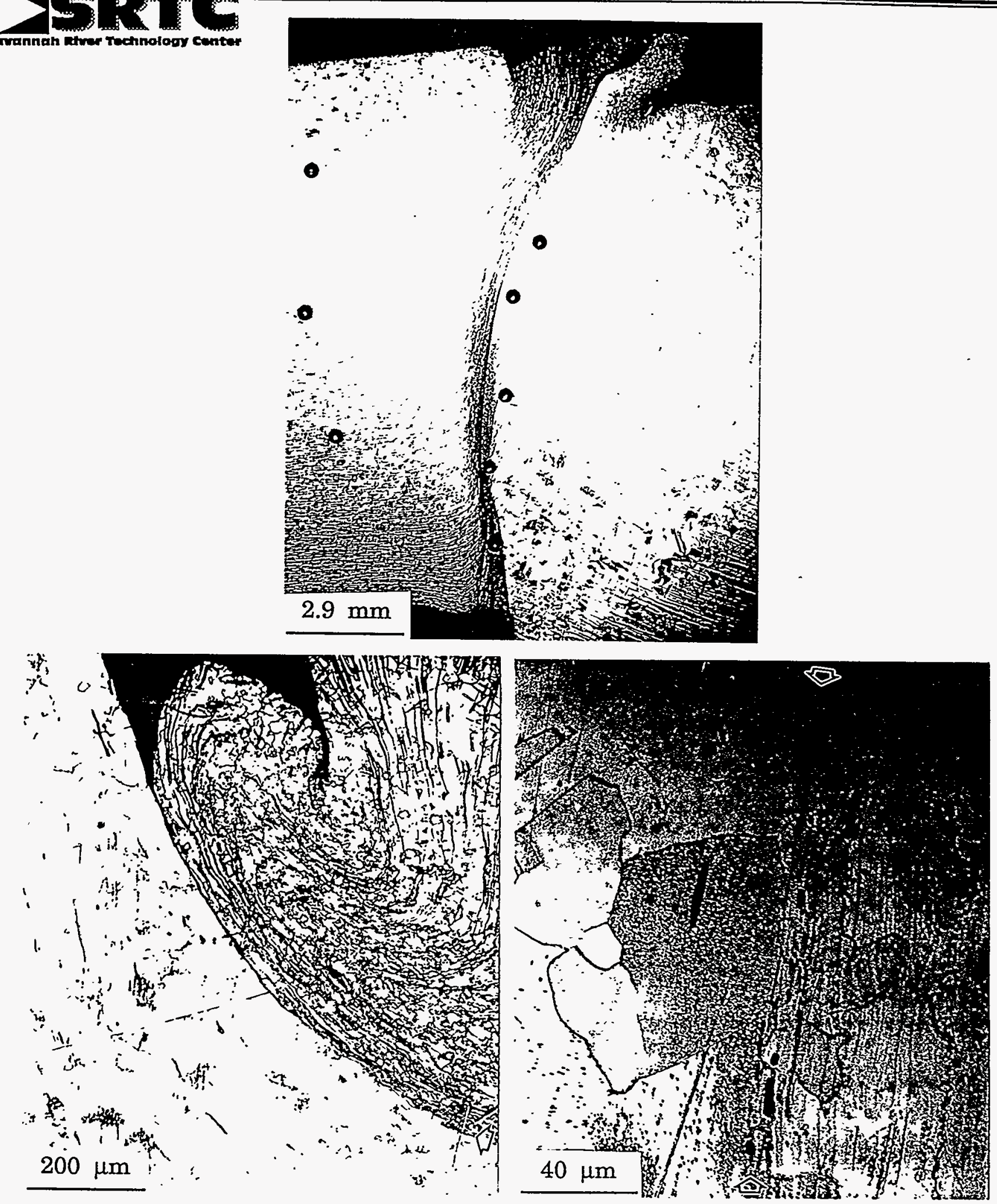

Sample KS05 Welded at Intermediate Parameter Settings. Weld Cross Section and Bond Line at Top.

Savannah River Technology Center Materials Technology Section 


\section{DSRTE}

3. स. -

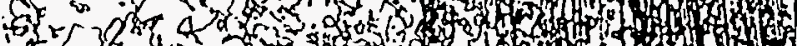
5.2n fon 40 . - A - .

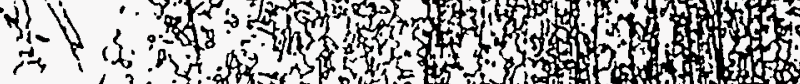

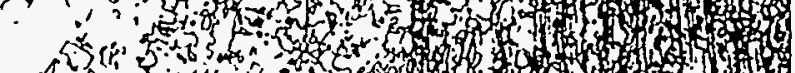
$=4$. (1)

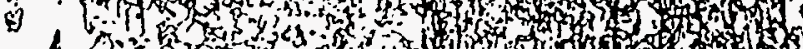
6. 350 , $14-5=0$.

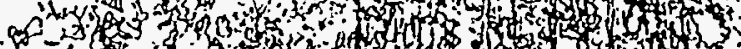

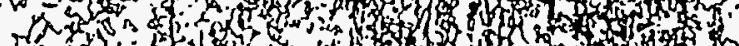

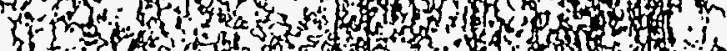
- $\quad$ r n $\therefore$.

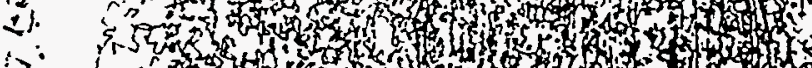

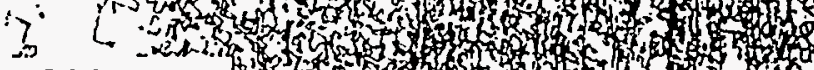
$200 \mu \mathrm{m}$

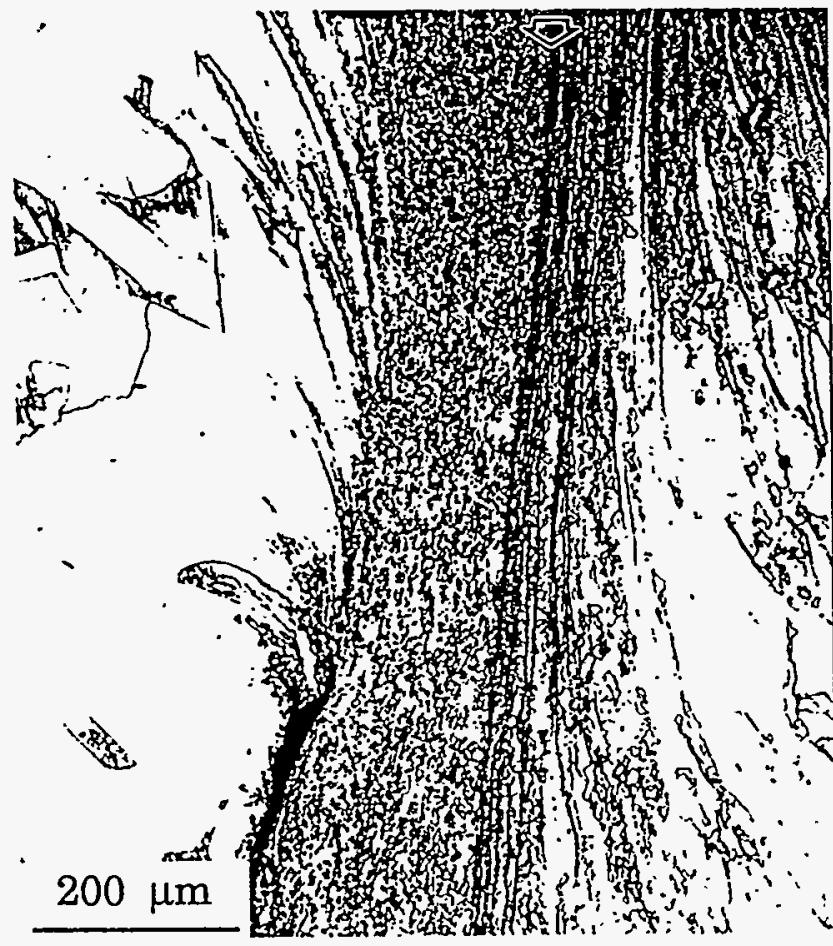

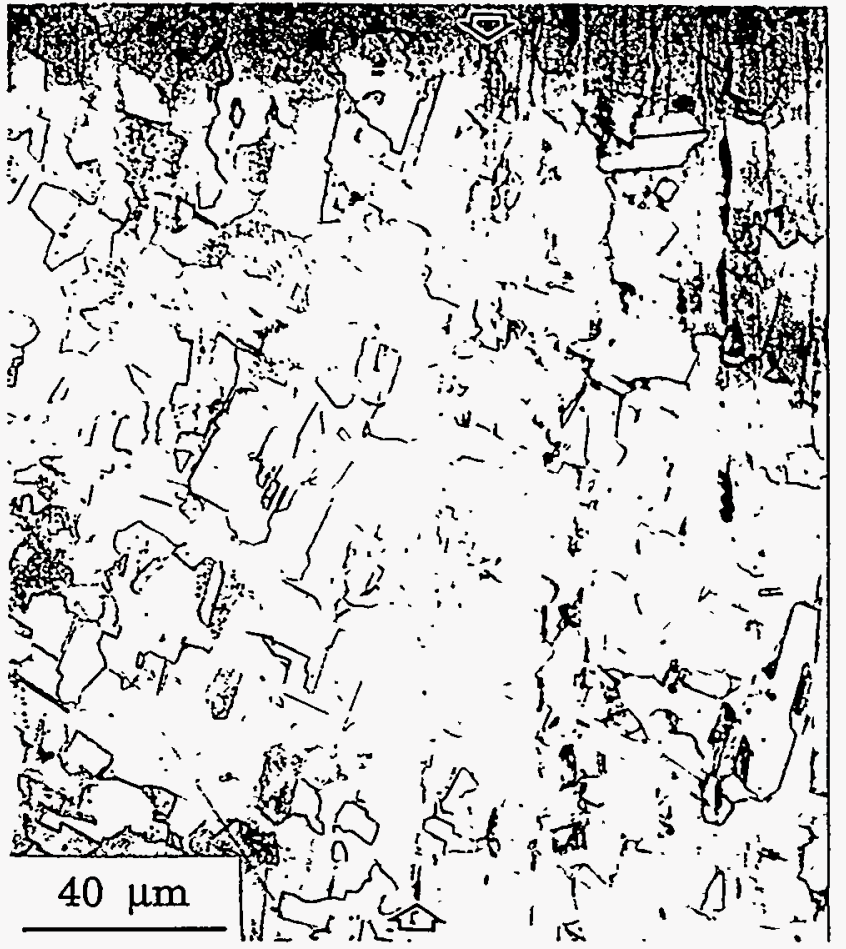

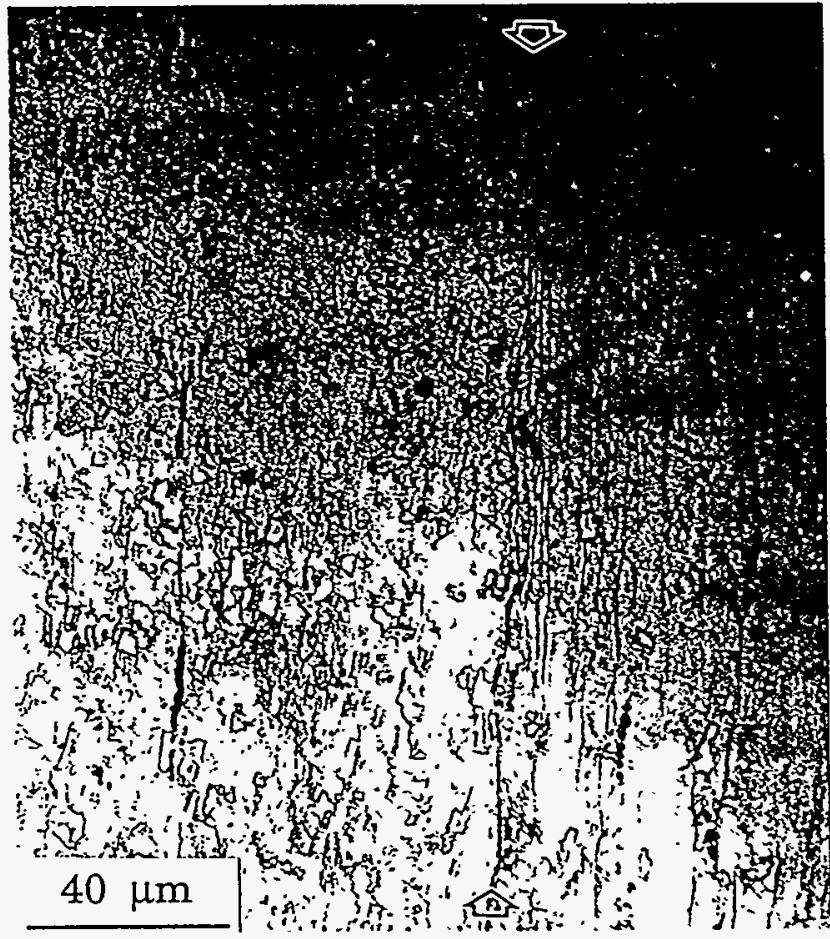

Sample KS05 - Bond Line at Center and Bottom. 


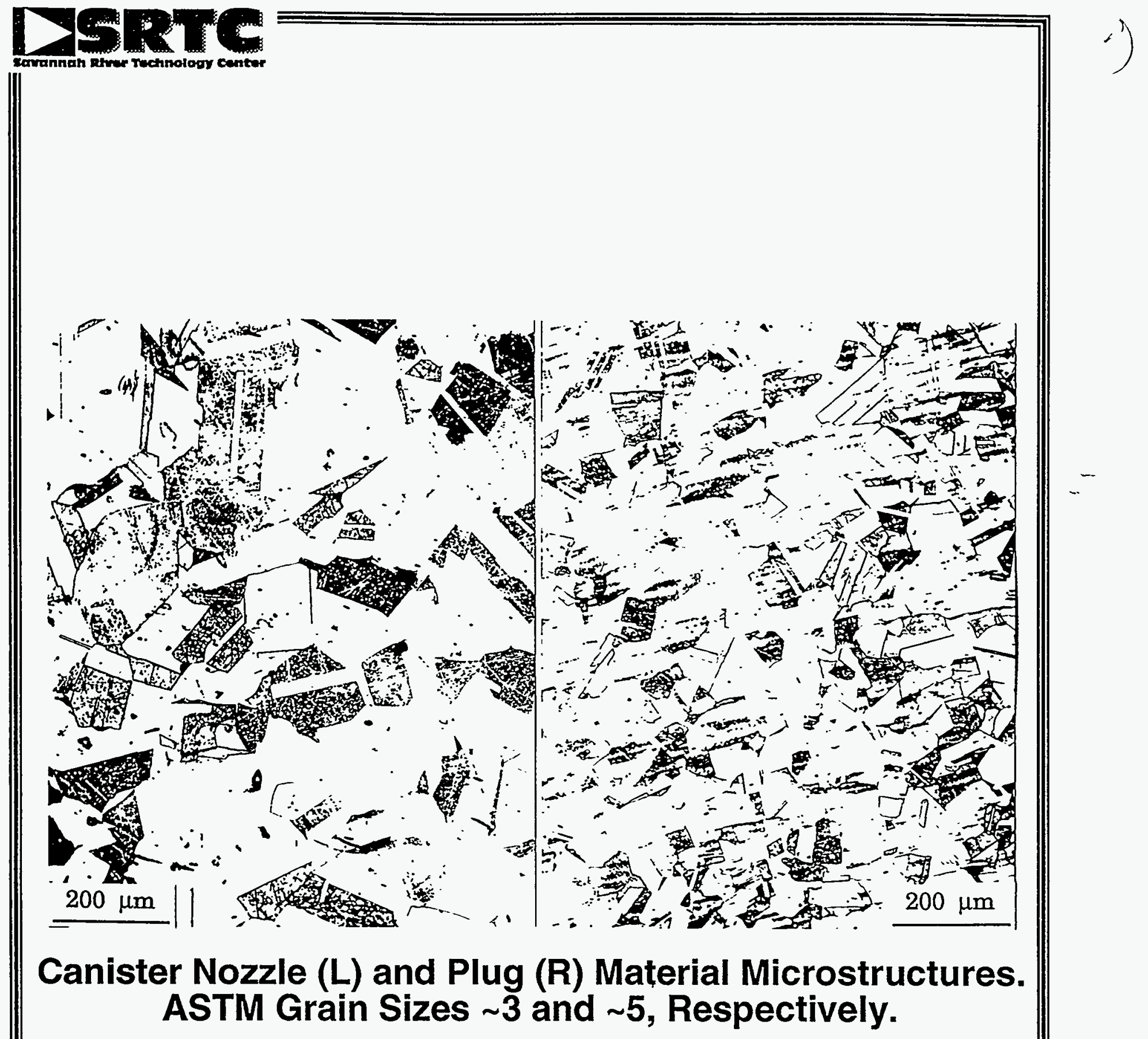




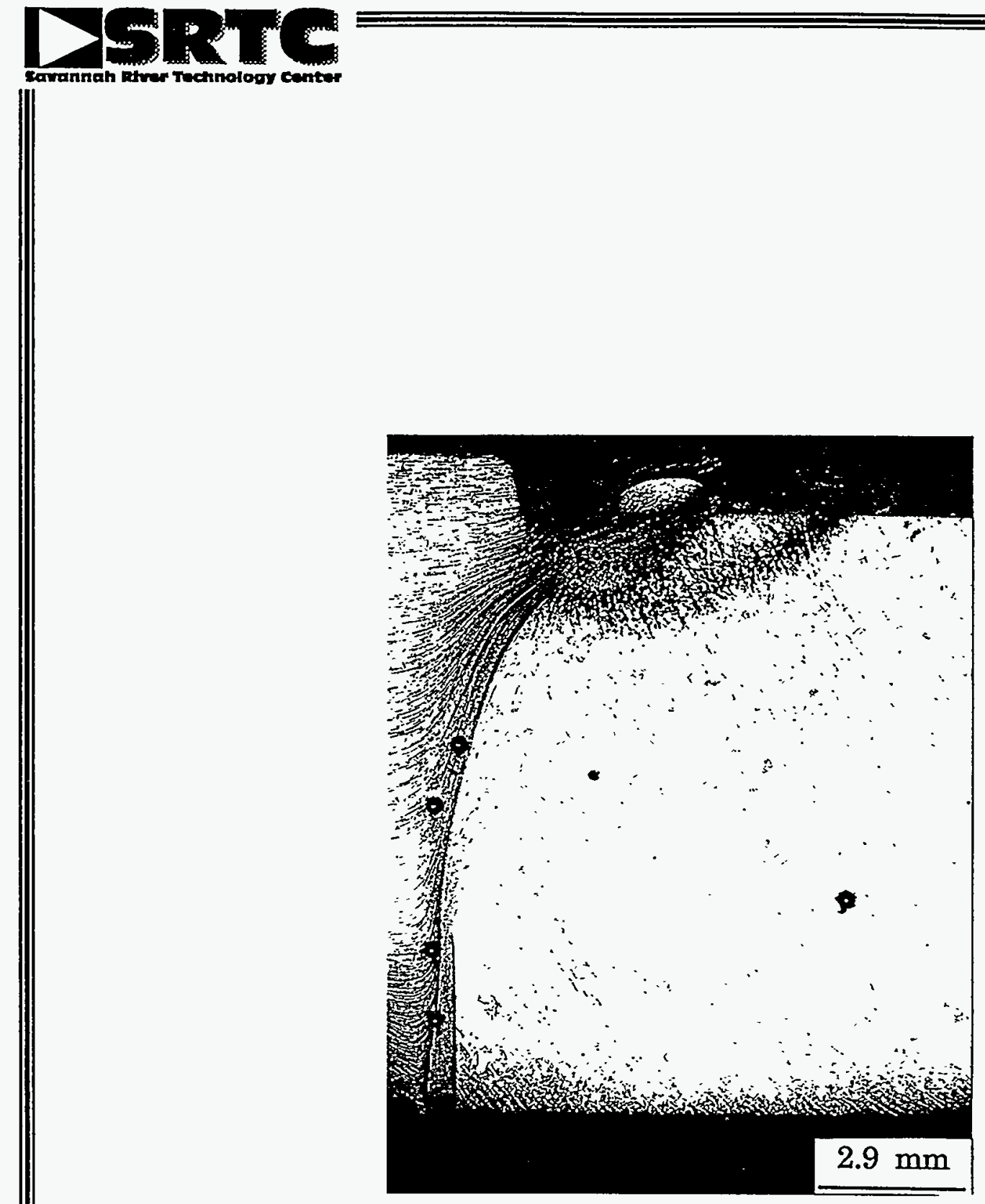

\section{Sample KS02 Welded at High Current and Time, Low Force.}




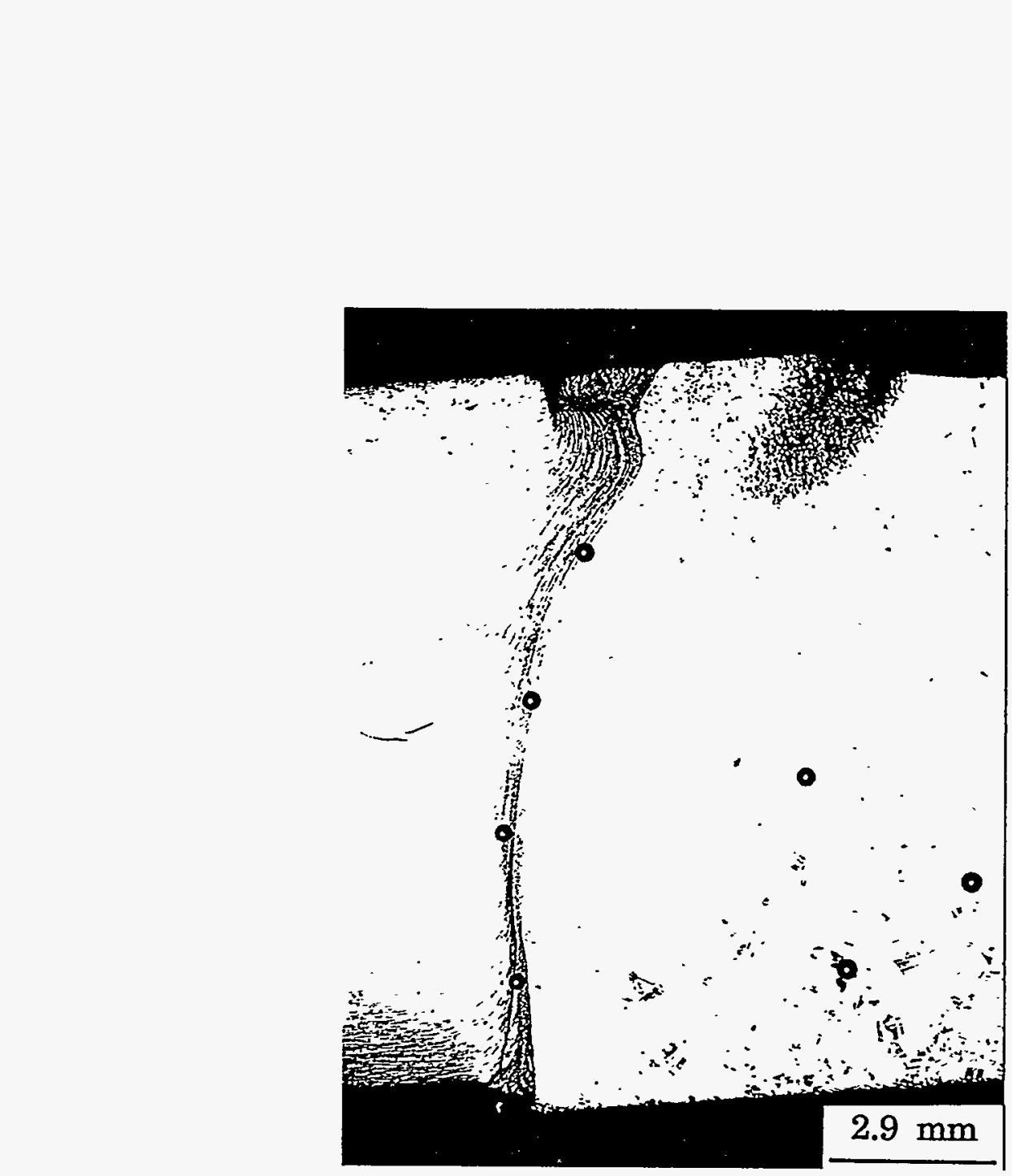

Sample KS07 Welded at High Force, Current and Time. 

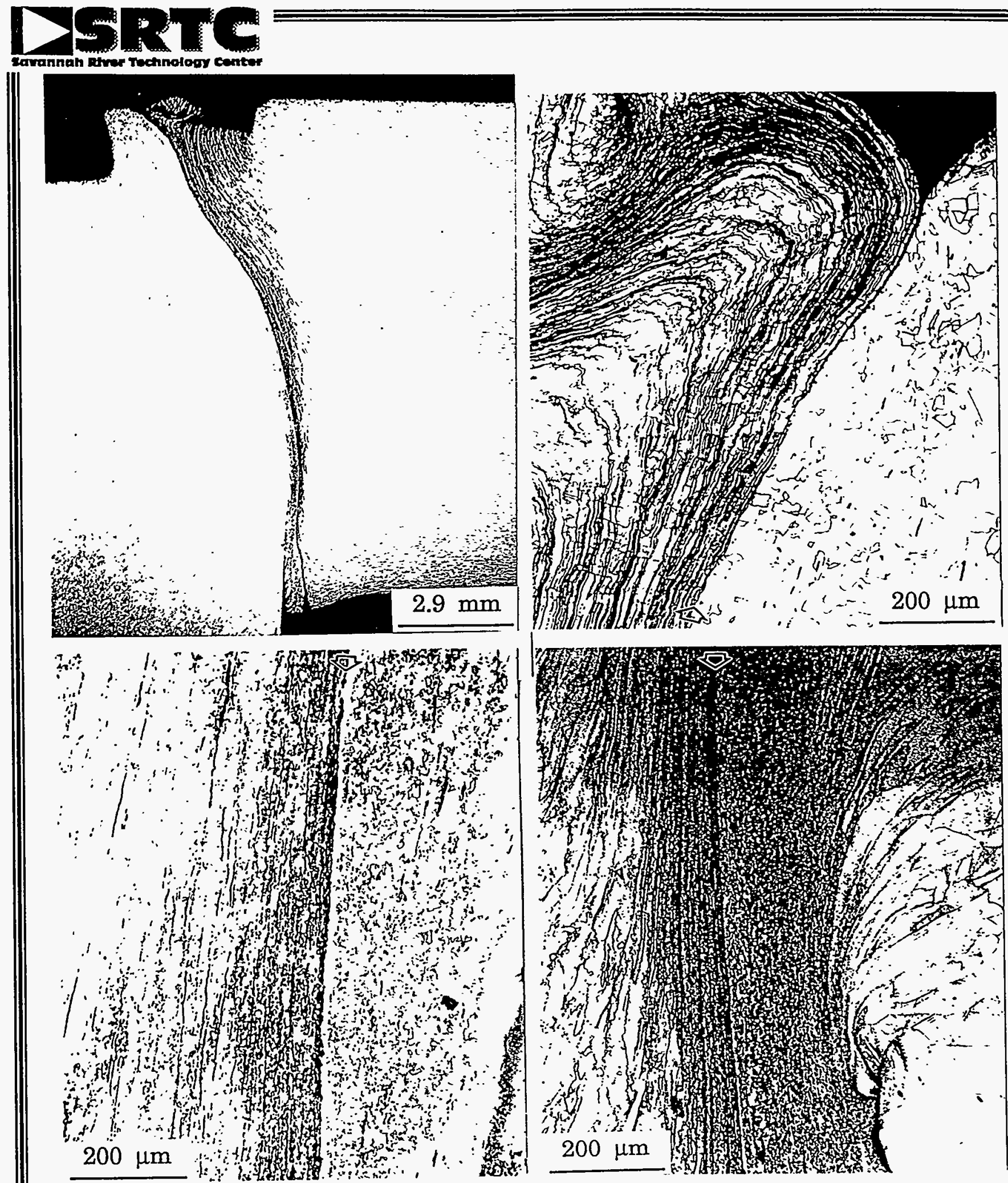

Sample KS41 Welded at Minimum Recommended Force, Current and Time. Cross Section and Bond Line at Top, Center and Bottom.

Savannah River Technology Center Materials Technology Section 


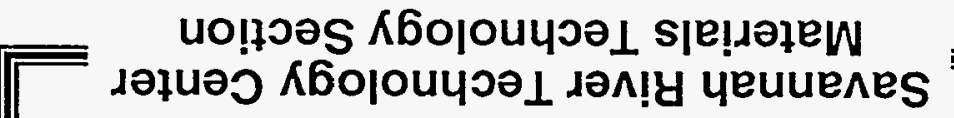

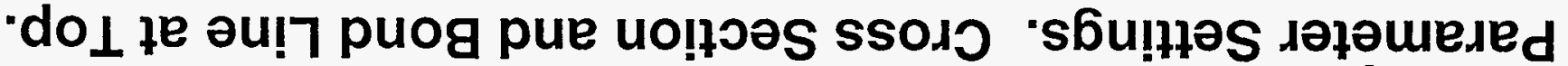

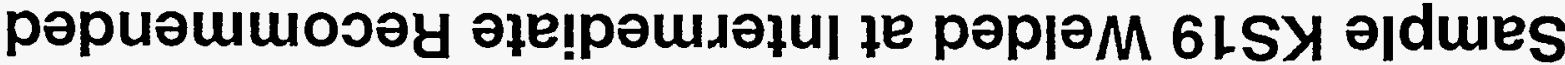
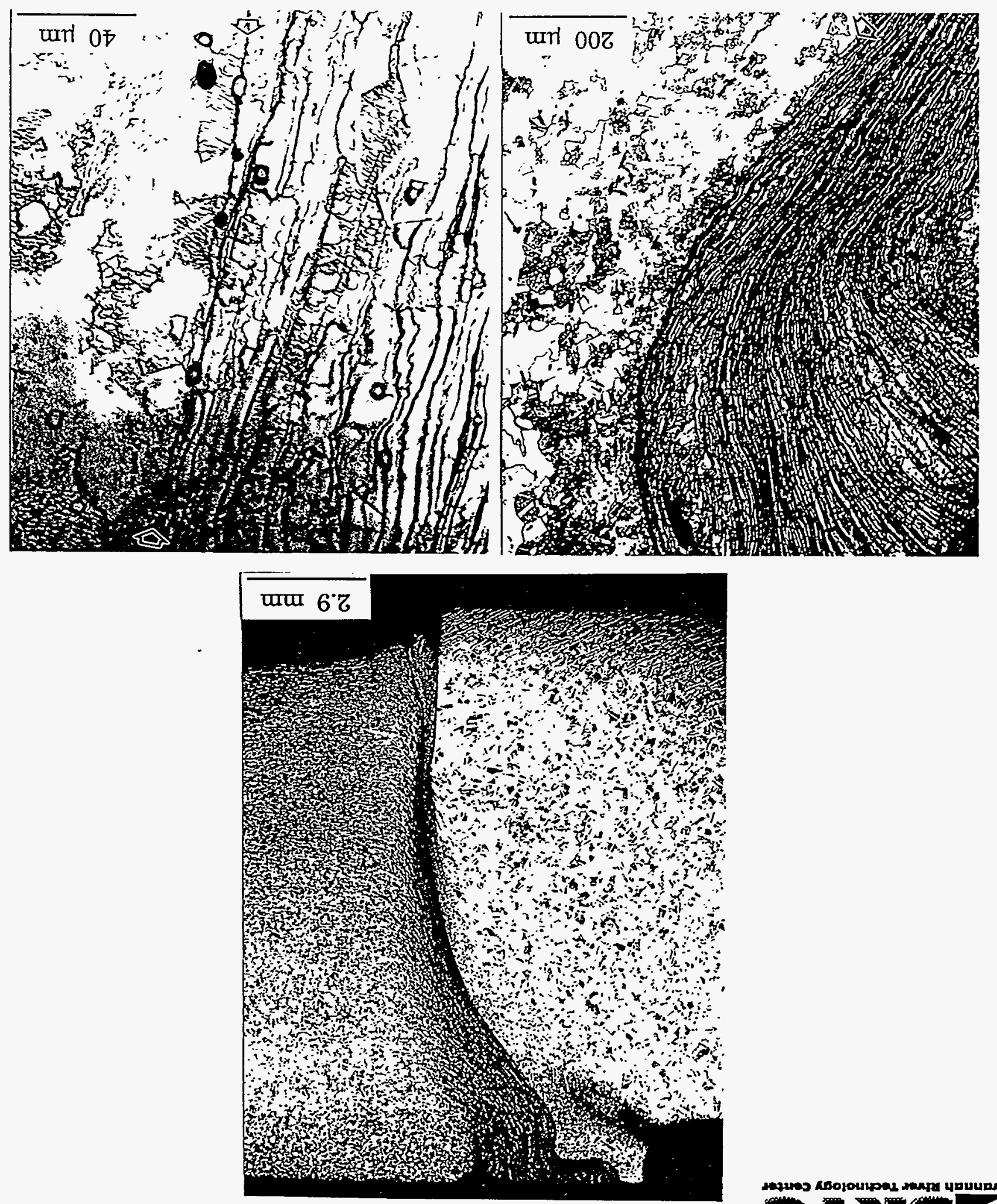

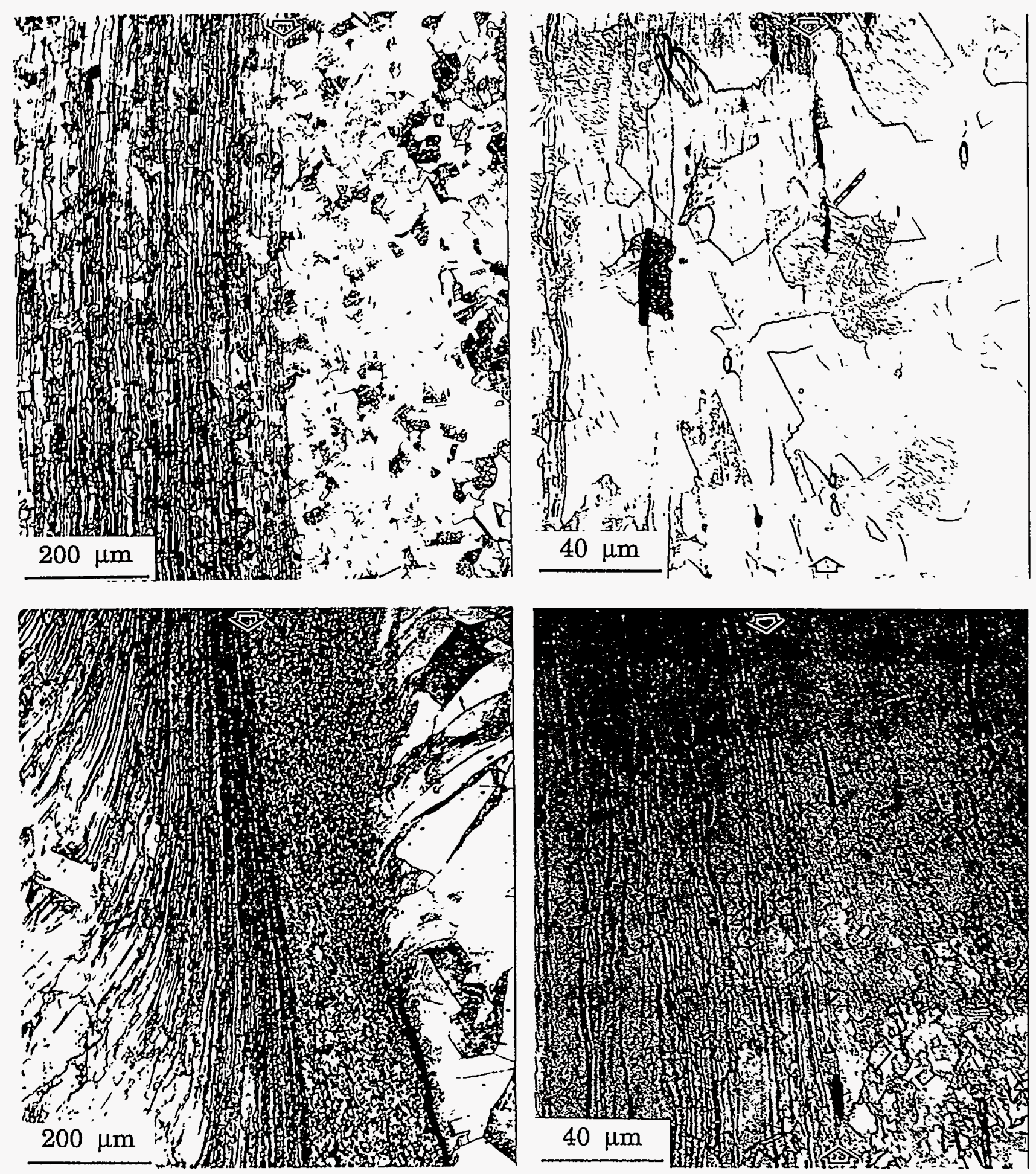

\section{Sample KS19 - Bond Line at Center and Bottom.}



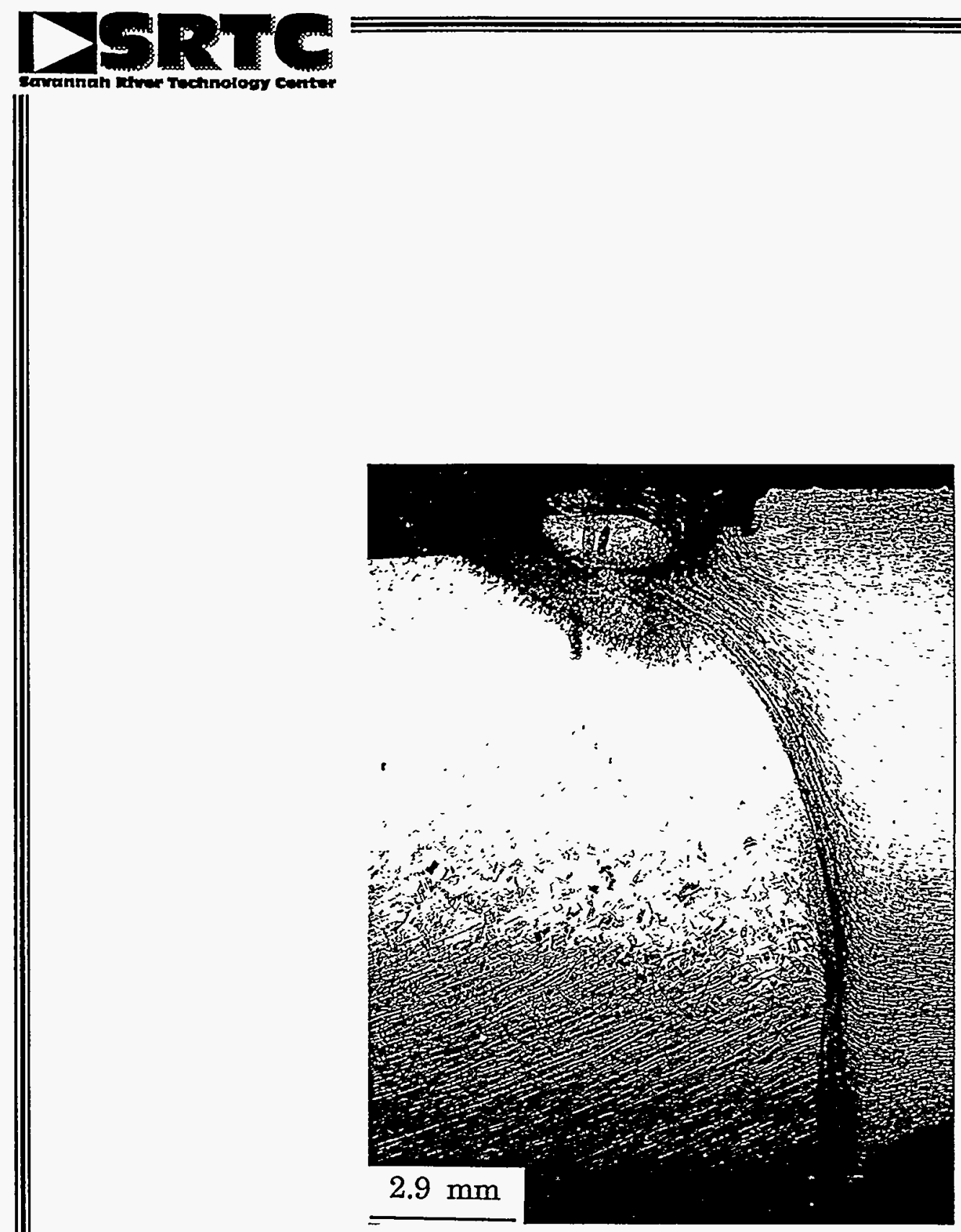

\section{Sample KS44 Welded at Maximum Recommended Current, Time and Low Force.}

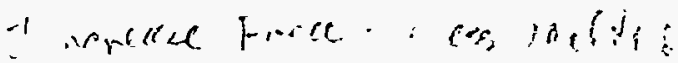

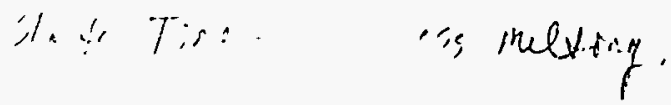


$(\therefore, \quad 72)$
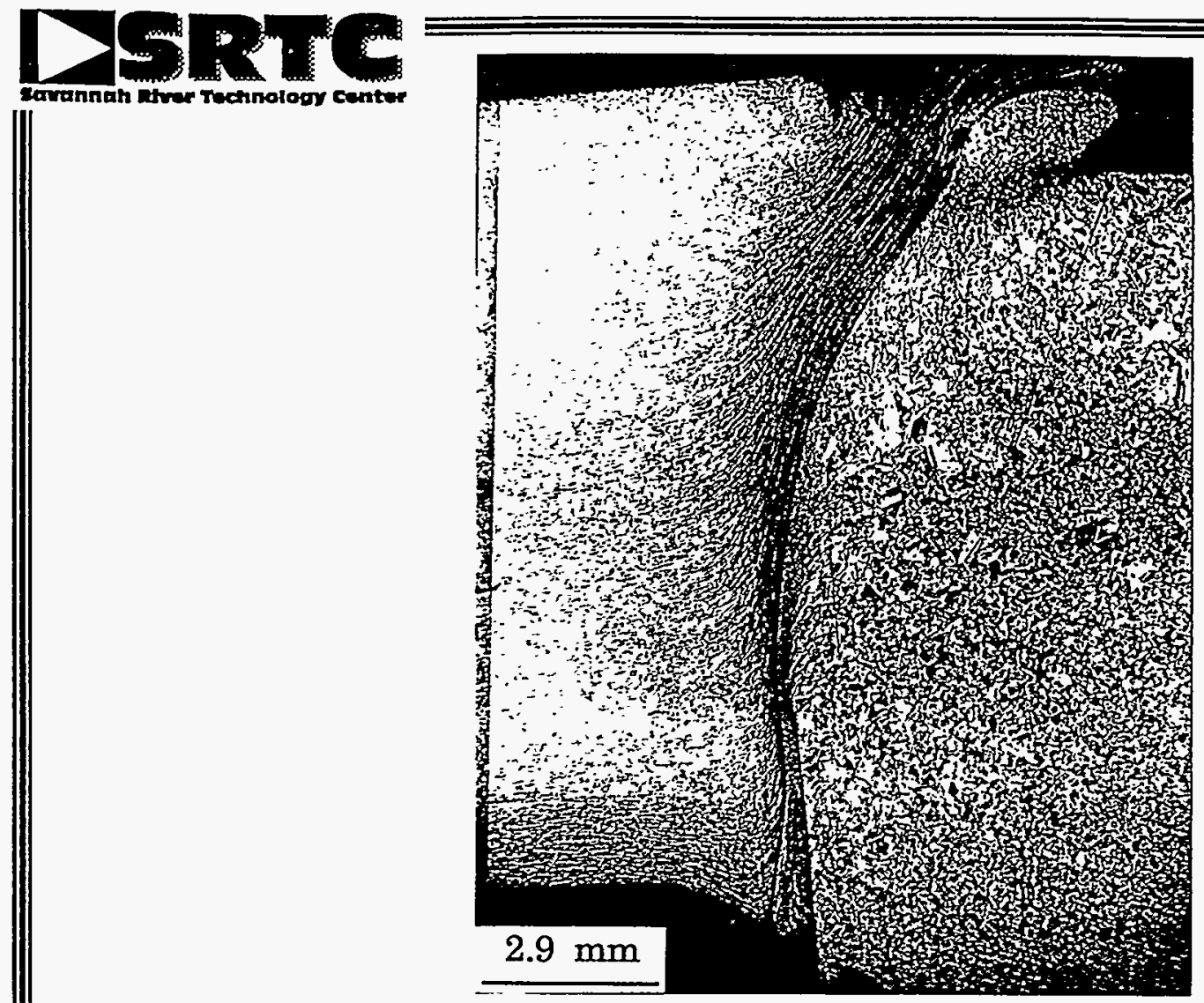

Parmeter space

||

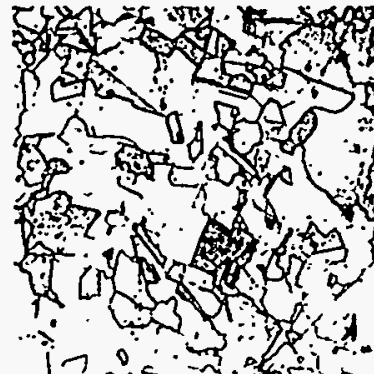

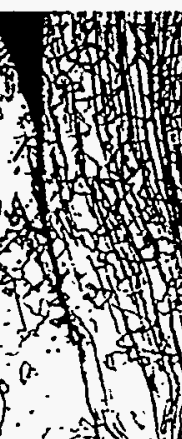

$\therefore$.

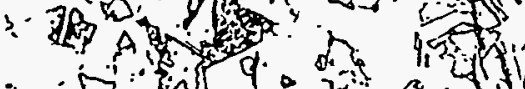

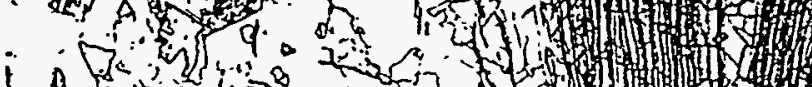

1

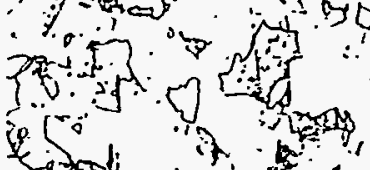

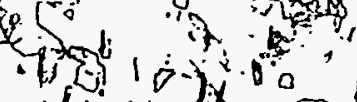

$200 \mu \mathrm{m}$

Sample CER-2 Welded at Less Than Intermediate Parameter Settings. Cross Section and Bond Line at Top. 


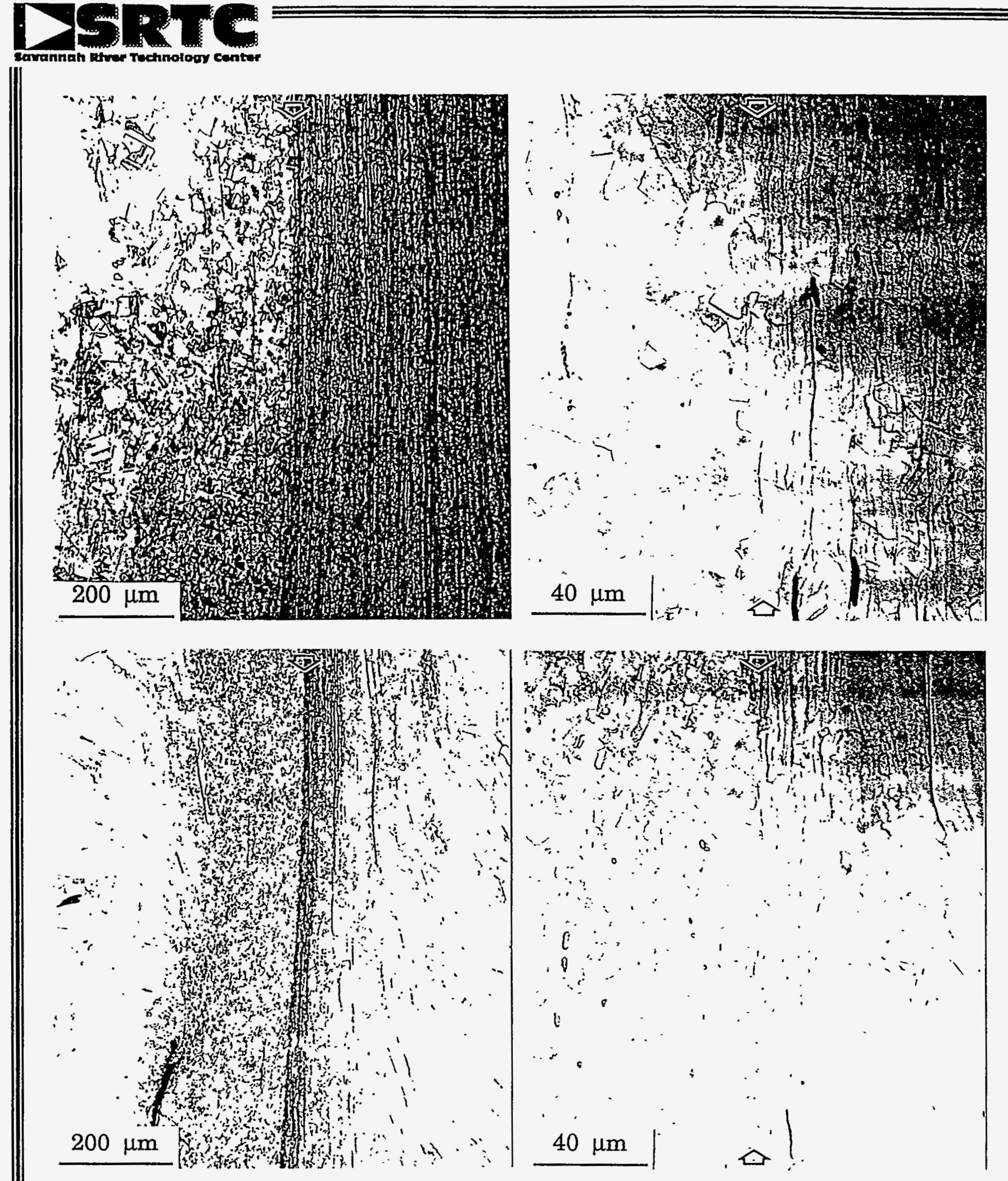

\section{Sample CER-2 - Bond Line at Center and Bottom.}




\section{DSRTC}

|II

\section{Weld Interface Length and Approx. Grain Size Along Interface. Minimum Interface Length $0.335 "$. \\ Starting Grain Sizes were $\sim 3$ (Nozzle) and 5 (Plug).}

$\begin{array}{lc}\text { Sample } & \begin{array}{c}\text { Weld Length } \\ \text { (in.) }\end{array} \\ \text { KS01 C2 } & 0.309 \\ \text { KS02 C2 } & 0.373 \\ \text { KS03 C2 } & 0.390 \\ \text { KS04 C2 } & 0.367 \\ \text { KS05 C1 } & 0.382 \\ \text { KS06 C1 } & 0.190 \\ \text { KS07 C2 } & 0.429 \\ \text { KS08 C1 } & 0.351 \\ \text { KS09 C1 } & 0.373 \\ \text { KS19 C1 } & 0.386 \\ \text { KS31 C2 } & 0.400 \\ \text { KS33 C2 } & 0.391 \\ \text { KS35 C1 } & 0.427 \\ \text { KS37 C2 } & 0.391 \\ \text { KS38 C2 } & 0.392 \\ \text { KS40A C2 } & 0.390 \\ \text { KS41 C2 } & 0.377 \\ \text { KS42 C2 } & 0.420 \\ \text { KS44 C2 } & 0.393 \\ \text { KS46 C1 } & 0.397 \\ \text { CER2 C1 } & 0.395 \\ \text { CER4 C2 } & 0.391 \\ \text { CER6 C2 } & 0.388\end{array}$

Top Grain Size
(ASTM No.)

10(Plug) 3(Nozzle)

6

7

8

7

7

6

6

7

7

7
7

8

8

8

8

8

7

8

8
7

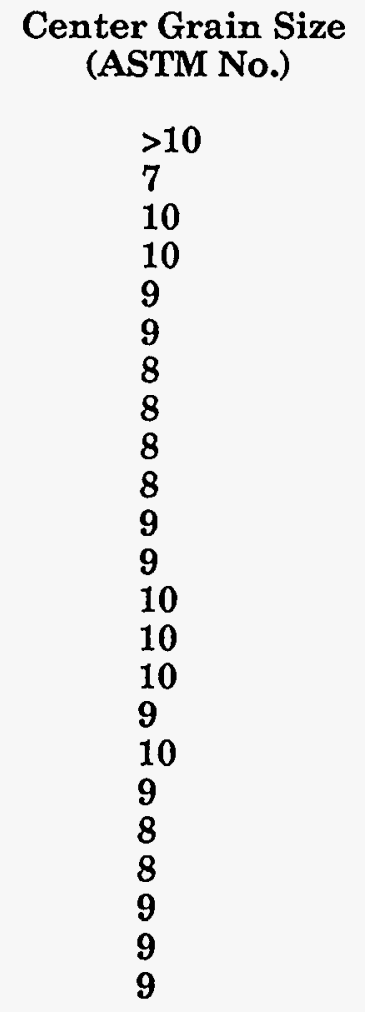

Bottom Grain Size (ASTM No.)

8(Plug) 6(Nozzle) 9

$>10$

$>10$

$>10$

9

10

10

10

$>10$

$>10$

$>10$

$>10$

$>10$

$>10$

$>10$

$>10$

10

10

$>10$

10
$>10$ 


\section{Conclusions}

- All Welds Produced Within Recommended Paramater Range Meet Acceptance Criteria as we inter preseded them

- Most Obvious Difference Among Acceptable Welds is Degree of Melting at Top

- Difficult to Relate Mechanical Property Variability to Weld Microstructures

- Careful Selection of Set-Point Within Recommended Range may Influence Properties of Welds

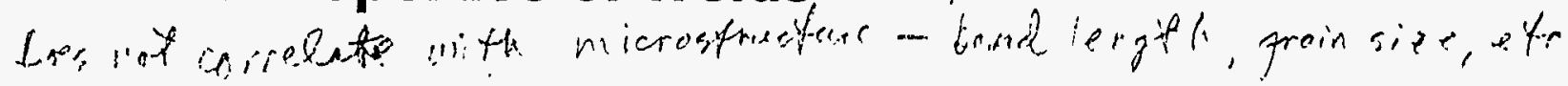




\section{Acknowledgements}

Tony Curtis, Phil DeMaere, Kricket Arbaugh

Ann Holston

Bill Kanne

Bruce Eberhard

Phil Kestin 